\title{
Urban Seismic Risk Index for Medellín, Colombia, based on probabilistic loss and casualties estimations
}

Mario A. Salgado-Gálvez, Centre Internacional de Metodes Numerics en Enginyeria (CIMNE) Universitat Politecnica de Catalunya, Barcelona, Spain. mario.sal.gal@gmail.com

Daniela Zuloaga Romero, Illinois Institute of Technology, Chicago,

United States of America. dzuloaga@hawk.iit.edu

César A. Velásquez, Centre Internacional de Metodes Numerics en Enginyeria (CIMNE)

Universitat Politecnica de Catalunya, Barcelona, Spain. cavelasquez@,cimne.upc.edu

Martha L. Carreño, Centre Internacional de Metodes Numerics en Enginyeria (CIMNE)

Universitat Politecnica de Catalunya, Barcelona, Spain. liliana@cimne.upc.edu

Omar-Darío Cardona, Instituto de Estudios Ambientales (IDEA), Universidad Nacional de Colombia Sede Manizales, Manizales, Colombia. odcardonaa@,unal.edu.co

Alex H. Barbat, Centre Internacional de Metodes Numerics en Enginyeria (CIMNE)

Universitat Politecnica de Catalunya, Barcelona, Spain. alex.barbat@upc.edu

\begin{abstract}
Medellín is the second largest city of Colombia with more than 2 million inhabitants according to the latest census and with more than 240,000 public and private buildings. It is located on an intermediate seismic hazard area according to the seismic hazard map of Colombia although no destructive earthquakes have recently occurred having as a consequence low seismic risk awareness among its inhabitants. Using the results of a fully probabilistic risk assessment of the city with a building by building resolution level and considering the dynamic soil response, average annual losses by sectors as well as casualties and other direct effects have been obtained and aggregated at county level. Using the holistic evaluation module of the multi-hazard risk assessment CAPRA platform, EvHo, a comprehensive assessment that considered the social fragility and lack or resilience at county level was performed making use of a set of indicators with the objective of capturing the aggravating conditions of the initial physical impact. The Urban Seismic Risk Index has been obtained at county level being useful to communicate risk to decision-makers and stakeholders besides making easy to identify potential zones that can be problematic in terms of several dimensions of the vulnerability. This case study is an example of how a multidisciplinary research on disaster risk reduction has helped to show how risk analysis can be of high relevance for decision-making processes in disaster risk management.
\end{abstract}

Keywords: Urban seismic risk index; urban resilience; holistic risk assessment; probabilistic seismic risk analysis. 


\section{INTRODUCTION}

Several probabilistic seismic risk analysis have been conducted worldwide at different resolution levels and with different objectives, estimating the physical damage in terms of mean damage ratios (MDR), average annual losses (AAL) and probable maximum losses (PML) (Ordaz et al. 2000; Barbat et al. 2010; Lantada et al. 2010; Salgado-Gálvez et al. 2013; 2014a; 2015a, Zuloaga et al. 2013; Marulanda et al. 2013; IBRD and The World Bank 2013; Cardona et al. 2014; Silva et al. 2014; Ahmad et al. 2014). Quantifying risk from a physical point of view, although important, is only the first step in a comprehensive disaster risk management scheme (Cardona et al. 2008a; 2008b; Cardona 2009; Marulanda et al. 2014) after which, it is important to further use those results in disaster risk management related strategies. It is clear that the physical is not the only dimension and hence those results can be used as input data for a comprehensive, holistic, risk analysis (Cardona 2001; Carreño 2006; Carreño et al. 2007, Carreño et al. 2012; 2014). A holistic approach has also been included in the MOVE framework (Birkmann et al. 2013), one that outlines key factors and different dimensions to be addressed when assessing vulnerability in the context of natural hazards, as considered herein.

This paper presents the complete and final results of the urban seismic risk index, USRi, estimation for the city of Medellín, Colombia based on a holistic approach for which a preliminary assessment had been previously conducted (Salgado-Gálvez et al. 2014b). Medellín is the second largest city in Colombia with more than 2.2 million inhabitants in the urban area and where $\mathrm{m}$ is located on a valley lies on an intermediate seismic faults can generate im 2010; Salgado-Gálvez into 16 counties (comunas),
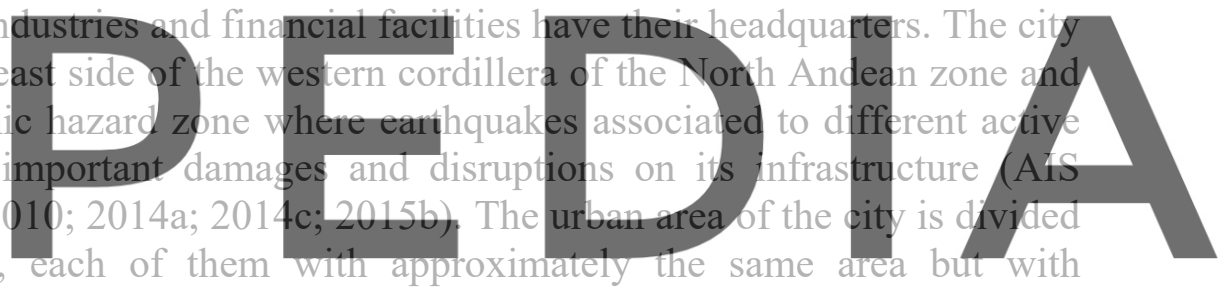

important differences from a social, economic and infrastructure perspective. During recent

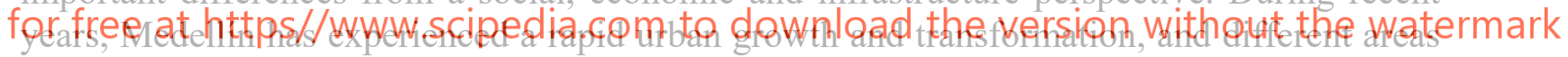
of the city have changed in terms of building classes, population density and availability of public spaces since low rise houses have been demolished to build high-rise structures to accommodate a larger amount of inhabitants, a process clearly identifiable in the mediumhigh and high income zones of the city.

A holistic risk assessment at urban level, which accounts for the vulnerability in several of its dimensions, requires a combination of the physical risk results with aspects that reflect social fragility and lack of resilience. In this context, social fragility is measured by means of variables that contribute to a soft risk related to the potential consequences over the social context, trying to capture issues related to human welfare such as social integration, mental and physical health, both at an individual and community level. On the other hand, lack of resilience is related to deficiencies in coping with the disasters and in recovering from them; these latest also contribute to the soft risk or the second order impact factor over exposed communities. Resilience is an adaptive ability of a socio-ecological system to cope and absorb negative impacts as a result of the capacity to anticipate, respond and recover from damaging events; therefore, it is important to know the lack of resilience since it has been proven to be an important factor of the overall vulnerability; aspects that are captured by means of a set of indicators.

For this case study, all the physical risk indicators are obtained starting from damage and loss 


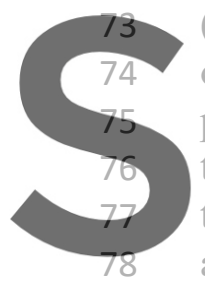

79

events that can be calculated by using fully probabilistic methodologies, such as the one of the CAPRA $^{1}$ platform, by convoluting hazard and vulnerability for the exposed elements (Cardona et al. 2010; 2012; Salgado-Gálvez et al. 2014a; Velásquez et al. 2014). For this study, the probabilistic physical risk results obtained by Salgado-Gálvez et al. (2014a) using CAPRA are complemented by estimating injured, deaths, homeless and unemployed on a building by building basis, also based on a fully probabilistic approach and grouping the results by counties.

The USRi is defined as a combination of a physical risk index, $R_{F}$, and an aggravating coefficient, $F$, in the following way: $U S R i=R_{F}(1+F)$ where $R_{F}$ and $F$ are composite indicators (Carreño 2006; Carreño et al. 2007). $R_{F}$ is obtained from the probabilistic risk results, while $F$ is obtained from available data regarding political, institutional and community organization aspects which usually reflect weak emergency response, lack of compliance of existing codes, economic and political instability and other factors that contribute to the risk creation process (Carreño et al. 2007; Renn 2008). This approach has also been applied at different resolution levels (Daniell et al. 2010; Burton and Silva 2014) and has been integrated in toolkits, guidebooks and databases for earthquake risk assessment (Khazai et al. 2014; 2015; Burton et al. 2014). Since not always the same information in terms of indicators is available for the area under study, each assessment constitute a challenge in the way that the descriptors are selected and in some cases calculated.

The multi-hazard risk assessment CAPRA platform holistic risk assessment module, EvHo, (CIMNE-RAG 2014) has been used in this work, which is a tool that incorporates directly the output files of the physical risk estination nade using CAPR probabilistic risk calculator module of the CAPRA platform. their corresponding weights to calculate $R_{F}$ and $F$; it also inc transformation functions, allowing the conve sit and calculates the aggravating coefficient for each analysis

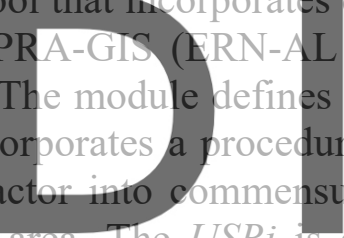
2011), the
factors and
ure based on
urable ynits
obtanned at county level according to the flowchart of Figure 1. All these computations are made possible

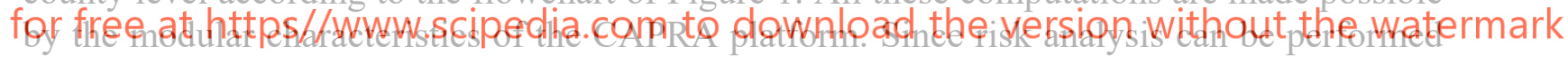
at different resolution levels, the tool allows the selection of the desired level, and if the risk has been calculated on a more detailed scale, it groups the results into the desired units.

For the social fragility $\left(F_{F S i}\right)$ and lack of resilience $\left(F_{F R j}\right)$ indexes, the user can define the number of factors and assign the weights to be used in each category; as in the case of the physical risk, the user can also select the transformation function in conjunction with the correspondent minimum and maximum limits for each factor. Once the above mentioned parameters are defined by the user, the Urban Seismic Risk Index (USRi) is calculated for the selected resolution level and results can be exported into tables, charts and maps in shapefile format.

\footnotetext{
${ }^{1}$ Comprehensive Approach to Probabilistic Risk Assessment (www.ecapra.org)
} 


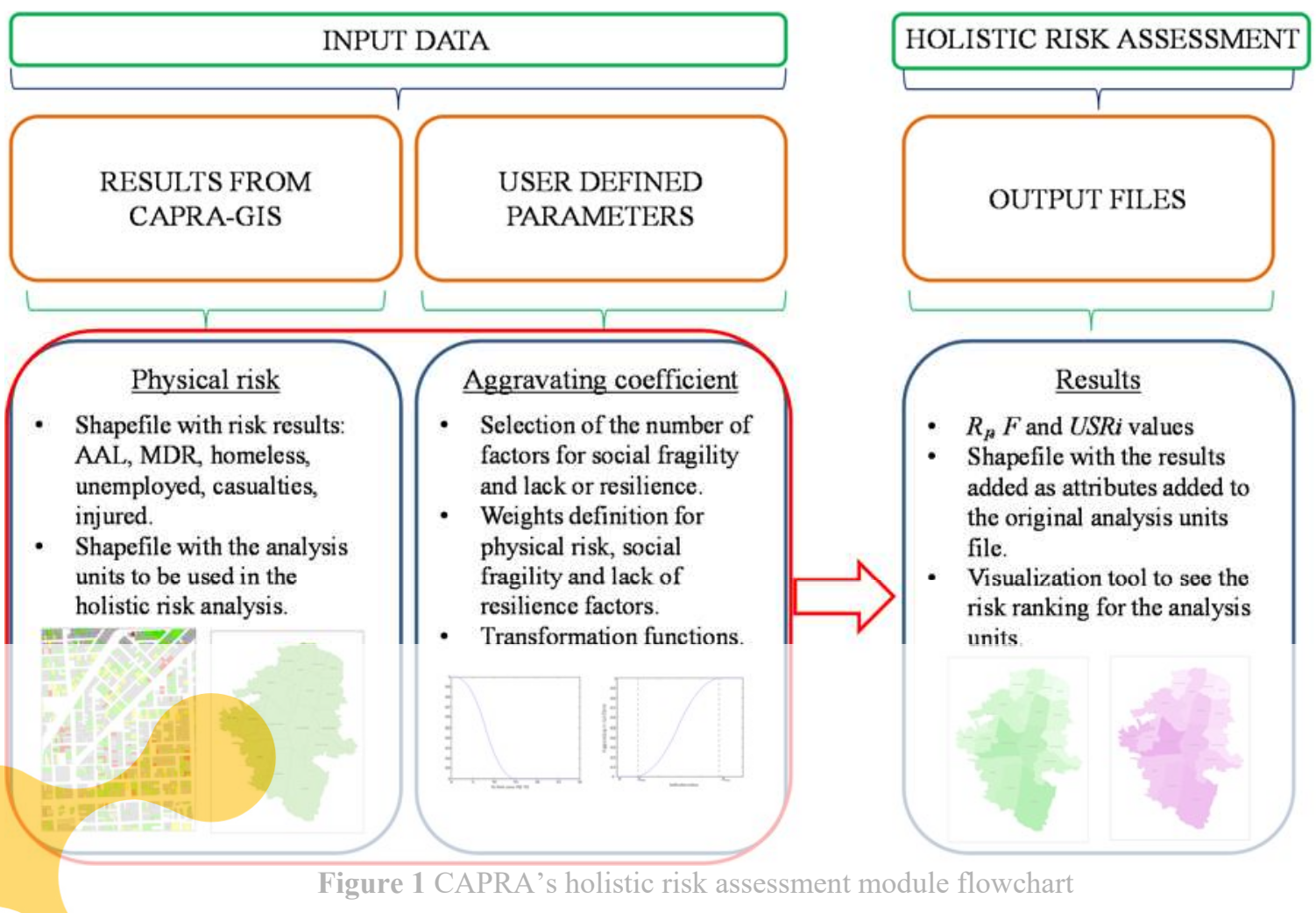

Obtaining risk results from a holistic perspective highlights the socioeconomic factors that contribute most to the aggravating coefficient, $F$, and they should help stakeholders and policy makers in the integral disaster risk management. Measuring risk with the same methodology in all counties of an urban area like Medellín allows a direct and appropriate comparison of the obtained results and it can help in prioritizing the areas for developing disaster risk reduction and management strategies. Also, the final result can be disaggregated and the main risk drivers after the holistic risk assessment can be highlighted and in this stage of the study, after complementing the preliminary results obtained by Salgado-Gálvez et al. (2014a), for the first time this procedure is performed and shown for the county with the highest USRi to clearly present which are the descriptors that are contributing the most in each of the indexes (physical risk, social fragility and lack of resilience) and then, the results are a useful basis for the development of specific strategies to improve their performance in their corresponding fields of action.

Holistic evaluations of seismic risk at urban level have been performed in recent years for different cities worldwide (Carreño et al. 2007; Marulanda et al. 2013) as well as at country level (Burton and Silva 2014) and have proven to be a useful way to evaluate, compare and communicate risk while promoting effective actions toward the intervention of vulnerability conditions measured at its different dimensions. Although at first it can be seen simply as another case study based on a well-known methodology, on the one hand, this study 


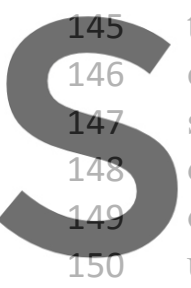

151

tactors.

Regişter for free approaches.

incorporates a set of probabilistic descriptors in the side of the physical risk that had never been assessed in Medellín while, on the other hand, since the main purpose is to raise risk awareness and, not a generally agreed practice on a holistic risk assessment framework exists, the development of case studies that consider different methodologies (Brink and Davidson 2014) to obtain the input data can serve as examples for future comparisons of the

This is the first time that a study following the above mentioned methodology is conducted with a high resolution in all the aspects (seismic hazard, exposure and socio-economic descriptors) and the results are useful to identify risk driver factors that are not associated only to the physical vulnerability of the dwellings but also to social and poverty factors that should be examined and tackled in an integral way, stressing out that poverty is not necessarily the same as vulnerability. The importance of risk analysis has been understood at different decision-making levels but the need of being incorporated as a development issue by governments is still on its way. Finally, it also constitutes an example of how an integrated research on disaster risk reduction can reduce the gap between the risk analysis and its relevance for risk management decision-making processes (Salgado-Gálvez et al. 2014b).

\section{PROBABILISTIC PHYSICAL SEISMIC RISK AND DIRECT IMPACT} ASSESSMENT

The seismic risk analysis from a holistic perspective requires the calculation of a set of factors that are related to the direct effects of the hazardous events on consequences in terms struck by an earthquak different categories a other factors are inemployed. This section presents the methodology 2.1 Physical seismic risk analysis methodology

154 155 156 157 158 159 160 161 162 163 164 165 166 167 168 169

For a fully probabilistic seismic risk analysis, different input data for the hazard, exposure and physical vulnerability are required. Seismic hazard is represented by means of a set of stochastic events generated using the program CRISIS 2007 (Ordaz et al. 2007), which is the seismic hazard module of CAPRA; each event associated to the different seismogenetic sources identified at country level (AIS 1996; 2010; Paris et al. 2000; Taboada et al. 2000; Pulido 2003; Salgado-Gálvez et al. 2010; 2015b); for each event, hazard intensities in terms of their first two statistical moments are obtained for different spectral ordinates to take into account the fact that structures with different dynamic characteristics have different earthquake solicitations for the same event. Since the city also has a seismic microzonation (SIMPAD et al. 1999) it has been considered in the analysis by determining spectral transfer functions for each homogeneous soil zone in order to calculate the hazard intensities at ground level. The exposure database consists of the portfolio of buildings, both public and private, and is comprised by 241,876 elements (Alcaldía de Medellín 2010) that have been identified, characterized and associated to a building class. Physical vulnerability is represented by means of vulnerability functions that allow both a continuous and probabilistic representation of the loss associated to different hazard intensities, in this case corresponding to the spectral acceleration for 5\% damping, an intensity measure that correlates well with the seismic performance of structures (Luco and Cornell 2007). More details about the employed 


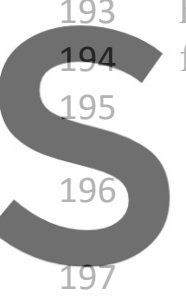

198

methodology and information for the physical risk analysis can be found in Salgado-Gálvez et al. (2014a).

Since all input data have been represented using a probabilistic approach, the loss calculation process can follow the methodology proposed by Ordaz (2000) and that is used in the CAPRA platform, where a convolution between the hazard and vulnerability of the exposed elements is performed. The main output of these assessments is the loss exceedance curve (LEC) which relates loss values in monetary units, with their annual exceedance rates. The LEC is calculated using the following expression (Ordaz 2000):

$v(l)=\sum_{i=1}^{N} \operatorname{Pr}\left(L^{>}\right.$l|Event $\left._{\mathrm{i}}\right) \cdot F_{A}\left(\right.$ Event $\left._{\mathrm{i}}\right)$

where $v(l)$ is the rate of exceedance of loss $l, N$ is the total number of earthquake events that comprise the stochastic set and conform with the seismic hazard in the area under analysis, $F_{A}$ (Event i) is the annual frequency of occurrence of the $i^{\text {th }}$ earthquake event, while $\operatorname{Pr}(L>l \mid$ Event i) is the probability of exceeding $l$, given that the $i^{\text {th }}$ event occurred. The sum of the equation includes all potentially damaging events from the stochastic set. The inverse value of $v(l)$ is the return period of the loss $l$, denoted as Tr. Once the LEC is obtained, other risk metrics such as the AAL can be obtained by calculating the area under the LEC. This metric constitutes the first physical risk factor required to be determined for the study presented herein. AAL can also be directly computed, leading to exactly the same value using the following expression: $A A L=\sum_{i=1}^{N} \mathrm{E}(L \mid$ Event
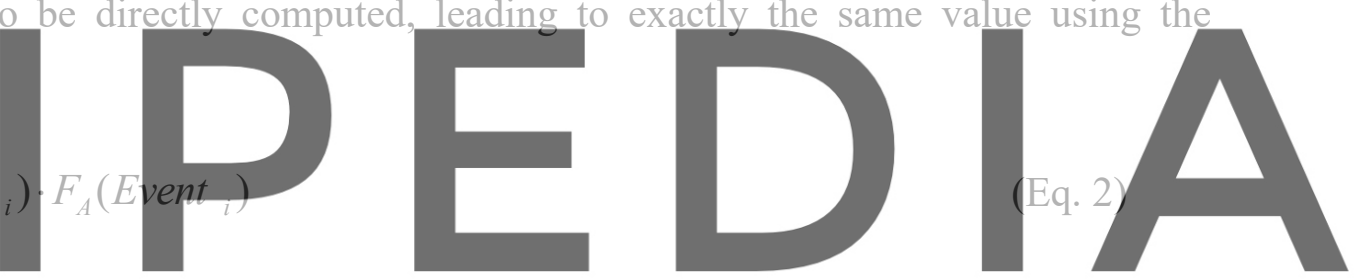

where $\mathrm{E}\left(L \mid\right.$ Event $\left._{i}\right)$ is the expected loss value given the occurrence of the $i^{\text {th }}$ event and

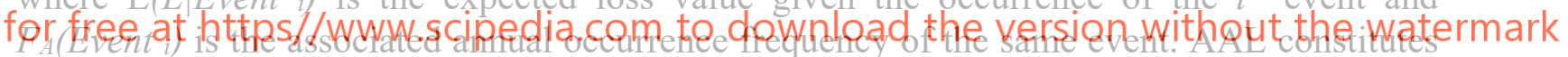

a robust indicator since it can represent risk at different resolution levels and also captures the participation on the overail risk of the smail and frequent events as well as the high and low frequency events while also being insensitive to uncertainty as is explained later.

Uncertainties related to hazard and physical vulnerability, defined according to their characteristics (temporal and spatial for the hazard and intensity-dependent for the vulnerability), are considered in the loss assessment; thus the result of the calculation process is a specific loss probability distribution for each hazard event. In the case of risk results in terms of losses, a Beta distribution is defined through a central value (mean) and its dispersion or uncertainty measure (variance). The latter is considered an appropriate probability distribution for modeling losses since results are always defined between 0.0 (no loss) and 1.0 (total loss) and since only direct losses are considered at this stage, the maximum possible loss is then the total exposed value.

\subsection{Physical risk results for Medellín}

Physical risk is calculated on a building by building resolution level and the obtained results are grouped by counties according to the location of each dwelling. It is well known that for the calculation of the AAL an arithmetical aggregation process can be applied to both counties and sectors. Table 1 shows the values in relative terms to the total exposed value by 
county and by sector in Medellín. Blank values (-) correspond to sectors that are not representative in the corresponding county. AAL seeks to give an overall and comprehensive representation of the risk levels, through a robust indicator and not only by loss values for earthquake events. AAL is calculated considering the participation of all the events, by multiplying the expected loss by its annual occurrence frequency, for each event. The AAL, when calculated by means of Equation 2, cannot have associated any uncertainty measure because it represents the loss results in annualized terms which, on the other hand, represent a mathematical expectation, not an uncertainty measure.

Table 1 Relative AAL (\%o) by county and by sector in Medellín

\begin{tabular}{|l|c|c|c|c|}
\hline \multirow{2}{*}{ County } & \multicolumn{4}{|c|}{ Sector } \\
\cline { 2 - 5 } & Commercial & Industrial & Institutional & Residential \\
\hline 1- Popular & 2.95 & - & - & 2.65 \\
\hline 2 - Santa Cruz & 1.26 & - & - & 1.59 \\
\hline 3 - Manrique & 2.79 & - & 3.11 & 2.67 \\
\hline 4- Aranjuez & 1.51 & - & 1.43 & 1.53 \\
\hline 5 - Castilla & 2.57 & 2.75 & 2.94 & 2.81 \\
\hline 6 - Doce de Octubre & 3.25 & - & - & 3.39 \\
\hline 7- Robledo & 1.93 & - & 2.20 & 2.21 \\
\hline 8- Villa Hermosa & 6.68 & - & - & 5.89 \\
\hline 9 - Buenos Aires & 6.03 & - & - & 5.70 \\
\hline 10 - La Candelaria & 3.68 & 3.70 & 3.76 & 3.41 \\
\hline 11 - Laureles Estadio & 3.72 & - & 3.27 & 3.55 \\
\hline 12 - La A mérica & $\mathbf{4 . 4 2}$ & - & - & 4.66 \\
\hline 13 - San Javier & 3.22 & - & - & $\mathbf{2 . 9 3}$ \\
\hline 14 - Poblado & 5.12 & 4.67 & - & 4.85 \\
\hline 15 - Guayabal & 3.80 & 3.38 & - & 3.40 \\
\hline 16 - Belén & 3.30 & - & 3.59 & 3.49 \\
\hline
\end{tabular}
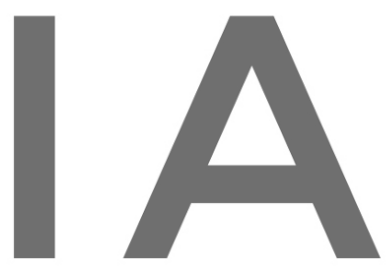

$232 \quad 2.3$ Death, injured, homeless and unemployed estimation for Medellín

Regł̋ß̊er for free at https//www.scipedia.com to download the version without the watermark

A fully probabilistic risk analysis is normally conducted for the complete set of hazardous events that comprise the hazard representation. However, for the purpose of estimating death, injured, homeless and unemployed, this study has been conducted for a single event where only one event is considered as $N$ in Equation 1. By setting the annual frequency of occurrence of the selected one to 1.0, Equation 1 will provide the probability of occurrence of the loss given the occurrence of the selected event, and not the annual frequencies of occurrence. Though the annual frequency of occurrence of it has been set equal to 1.0, and it represents a deterministic approach for the temporal probability of occurrence, hazard intensities are computed for the first two statistical moments representing the hazard uncertainties that, together with the vulnerability uncertainties, are included in the loss calculation process as explained above; therefore, the loss calculation is still probabilistic.

The event was chosen out of the more than 2,500 included in the stochastic set with the selection criteria of that event generating a direct economic loss of similar order of magnitude than that of a 500 years mean return period. That value is read from the LEC shown in Figure 2 and that return period is considered of relevance for the design of emergency plans in Colombia (SDPAE 2002). It is important to bear in mind that the return period of the loss is different from the return period of the seismic event since, in this case, there is correlation in the losses and uncertainties in the ground motion and physical vulnerability values (Bazzurro and Luco 2005; Bommer and Crowley 2006; Park et al. 2007; Crowley et al. 2008; SalgadoGálvez et al. 2014a). The expected loss for the selected return period obtained from the LEC 
is estimated in around 12 billion USD $^{2}$ which represents about $14 \%$ of the total exposed value. Loss exceedance rates are calculated by using the total probability theorem and because of that, for any loss level, the exceedance rate is calculated as the sum of all the events with probability of exceeding said loss level. In this case, the uncertainty is being considered in the calculation of the exceedance probabilities and then, the annual exceedance rates obtained cannot have associated an uncertainty measure because they are probabilities calculated for a specific loss value.
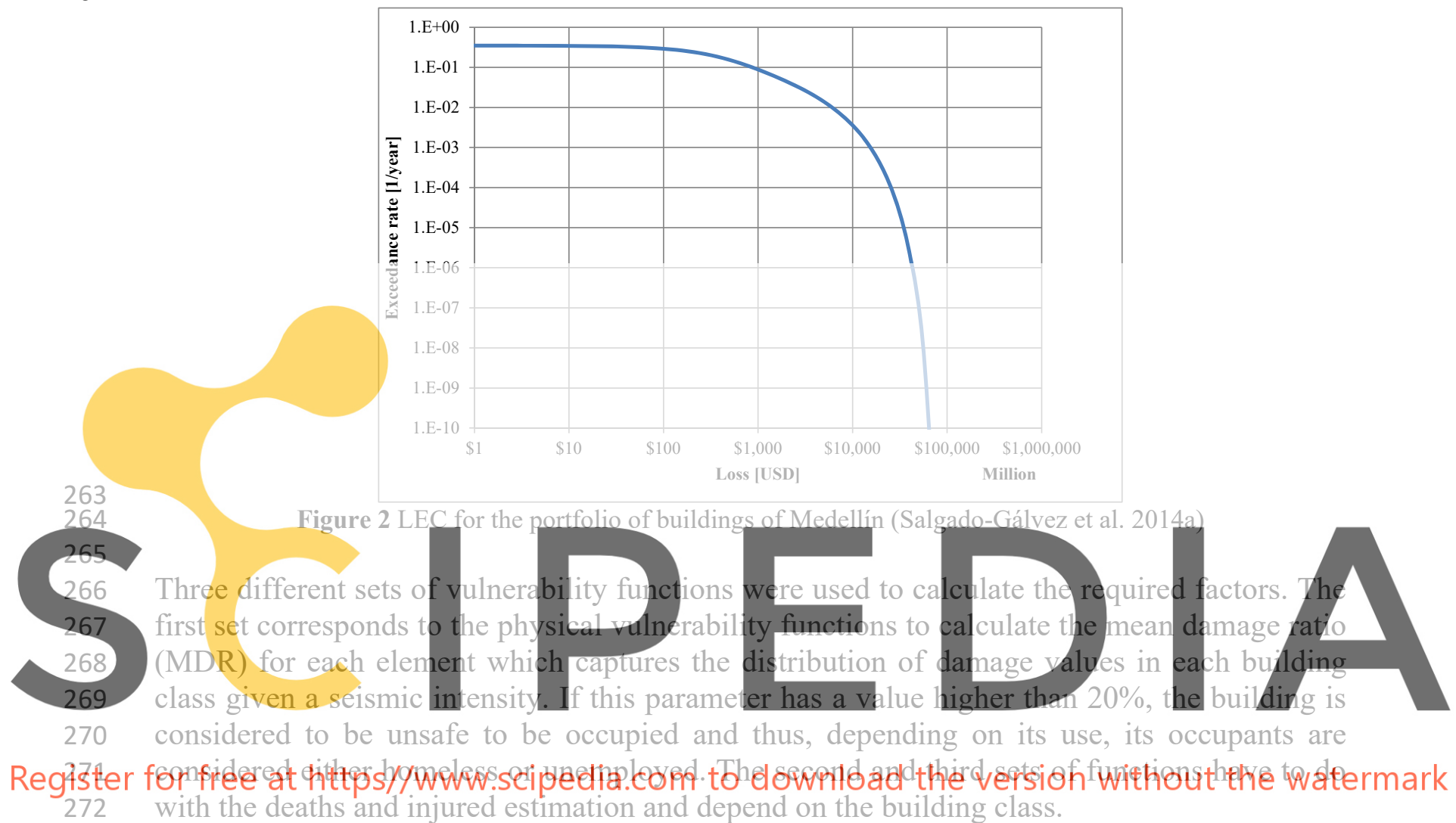

\section{0}

For the estimation of deaths and injuries, fatality rates proposed by Jaiswal et al. (2011) were selected and also, a workday scenario is assumed. Given that occupation is a dynamic parameter and the day and time of the earthquake cannot be established with this approach, a

Table 2 General characteristics of the selected event

The selected seismic event is associated to the Romeral Fault System which is the one that controls the seismic hazard level for medium and long return periods in Medellín (AIS 2010). Table 2 shows the characteristics of the selected event in terms of location, depth and magnitude.

\begin{tabular}{|c|c|}
\hline Longitude & $-75.69^{\circ}$ \\
\hline Latitude & $6.24^{\circ}$ \\
\hline Depth & $12 \mathrm{Km}$ \\
\hline Magnitude & 6.9 \\
\hline Mean return period & 306 Years \\
\hline
\end{tabular}

${ }^{2}$ An exchange rate of $1 \mathrm{USD}=3,000 \mathrm{COP}$ has been used in this study

Natural Hazards, 80(3), 2016, 1995-2021 
Table 3 shows the estimated direct impact results of the selected event in terms of economic loss, deaths, and injuries as well as homeless and unemployed, while Figure 3 shows the shakemap in terms of the peak ground acceleration (PGA), at bedrock level, of the selected event in the area of analysis. That value was modified through the transfer functions to account for the local dynamic soil response. Figure 4 shows the MDR distribution for Medellín.

Table 3 Result of the direct losses for the selected event

\begin{tabular}{|l|c|}
\hline Seismogenetic source & Romeral Fault System \\
\hline Expected loss (Million USD) & 10,963 \\
\hline Deaths & 51,780 \\
\hline Injuries & 68,165 \\
\hline Homeless & 177,671 \\
\hline Unemployed & 37,547 \\
\hline
\end{tabular}

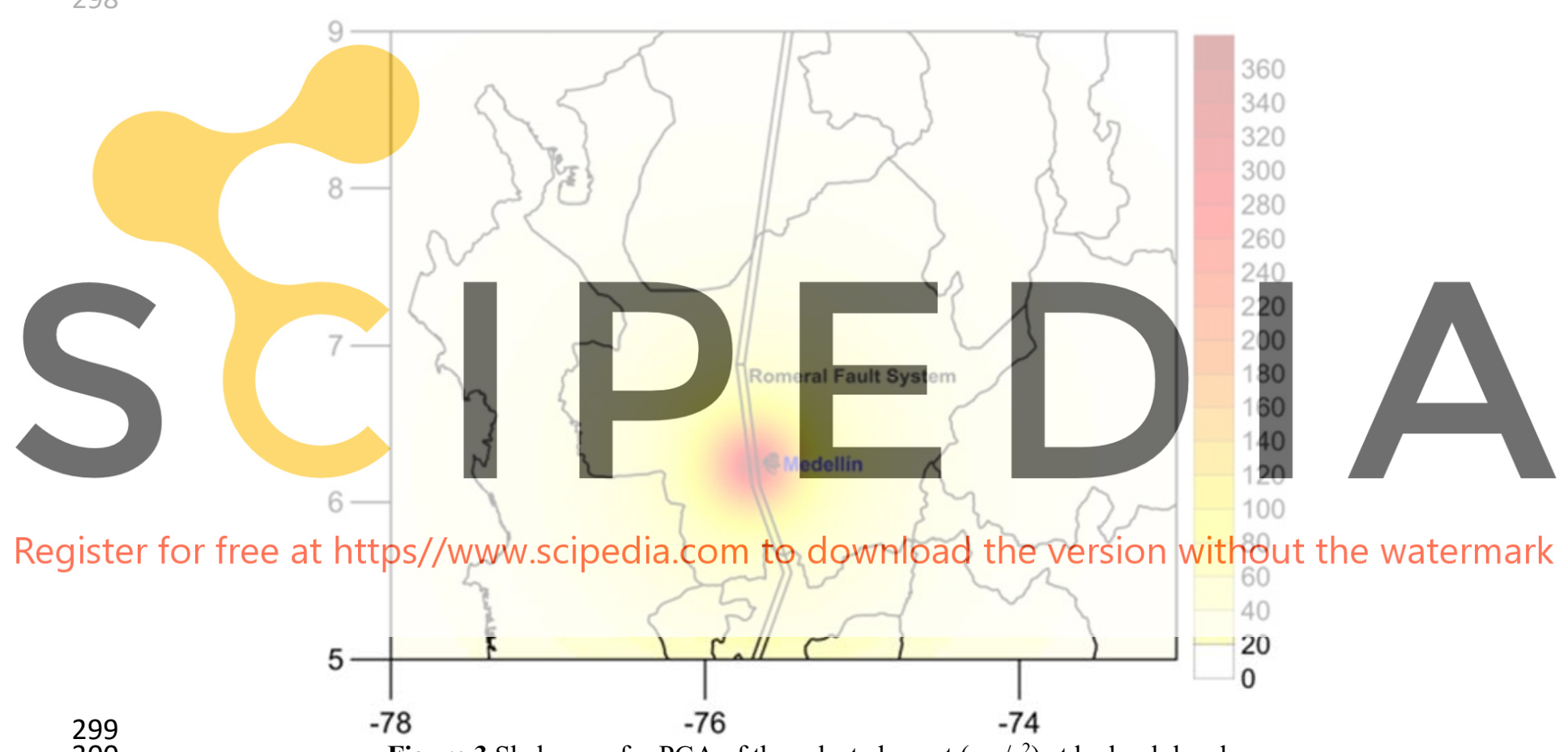

Figure 3 Shakemap for PGA of the selected event $\left(\mathrm{cm} / \mathrm{s}^{2}\right)$ at bedrock level 


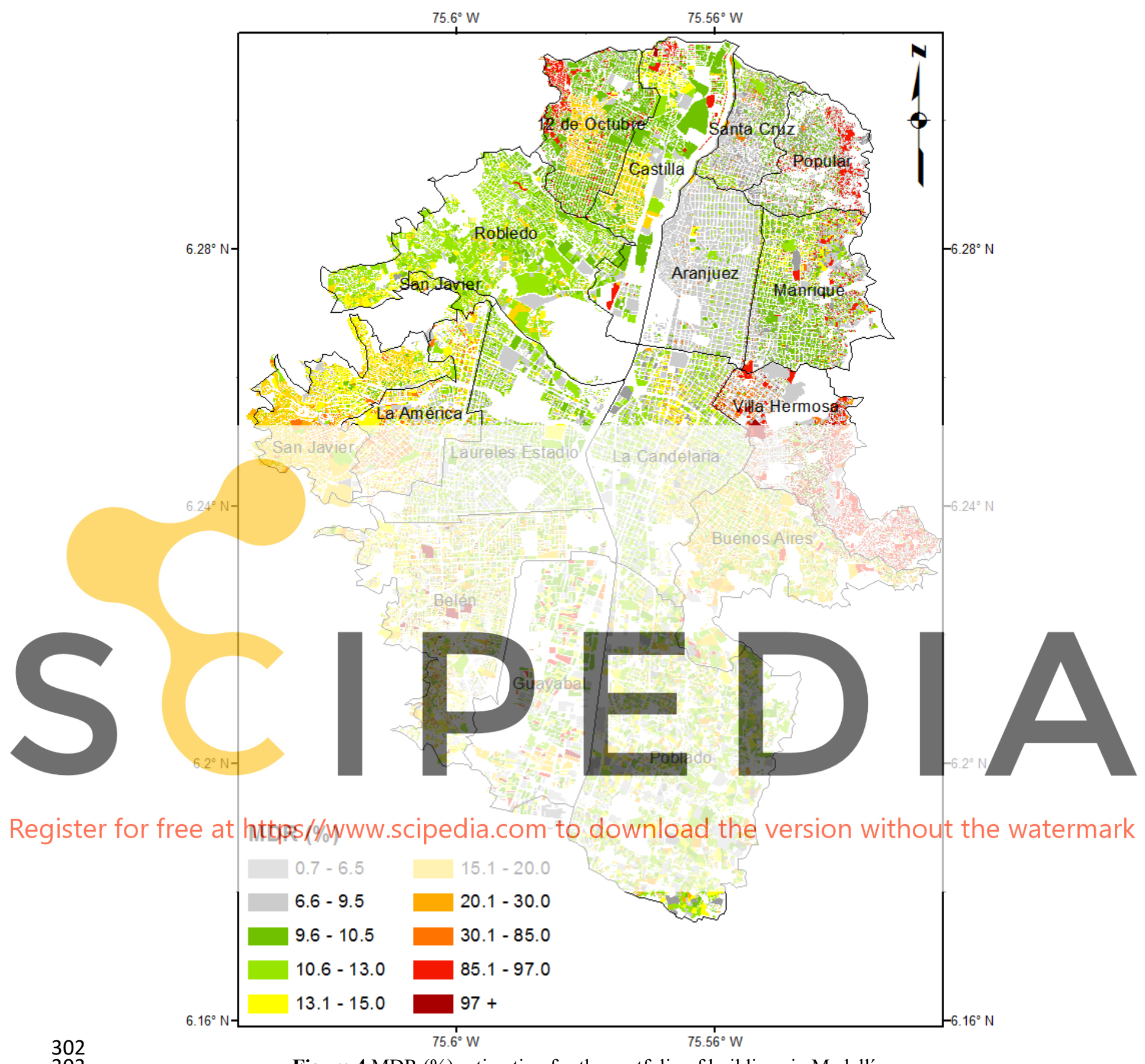

Figure 4 MDR (\%) estimation for the portfolio of buildings in Medellín

From the obtained results it can be seen that the highest MDR occurs in Villa Hermosa County which is located on the eastern part of the city where the high structural vulnerability is due to the large number of masonry units combined with the amplification factors in the short period range given the soil characteristics of the city (SIMPAD et al. 1999). Though Aranjuez County has a significant participation of masonry dwellings, because of local soil response characteristics, far less damage and losses are observed for this event. More details about the characteristics of the assets as well as the assigned vulnerability functions are given by Salgado-Gálvez et al. 2014a. To better understand the building stock distribution along the city, Table 4 shows the percentage of building classes and the total number of dwellings by County. 
Table 4 Building class distribution by County

\begin{tabular}{|l|c|c|c|c|c|c|c|}
\hline \multirow{2}{*}{ County } & \multicolumn{7}{|c|}{ Building class } \\
\cline { 2 - 8 } & Mas onry units & Wooden units & $\begin{array}{c}\text { Steel } \\
\text { units }\end{array}$ & $\begin{array}{c}\text { Reinforced } \\
\text { concrete } \\
\text { frames units }\end{array}$ & $\begin{array}{c}\text { Reinforced } \\
\text { concrete shear } \\
\text { wall units }\end{array}$ & $\begin{array}{c}\text { Non- } \\
\text { engineered } \\
\text { units }\end{array}$ & $\begin{array}{c}\text { Number of } \\
\text { dwellings }\end{array}$ \\
\hline 1- Popular & $40.1 \%$ & $30.1 \%$ & - & - & - & $29.8 \%$ & 16,629 \\
\hline 2 - Santa Cruz & $65.5 \%$ & $29.7 \%$ & - & - & - & $4.9 \%$ & 13,016 \\
\hline 3 - Manrique & $85.0 \%$ & - & - & $15.0 \%$ & - & - & 21,037 \\
\hline 4- Aranjuez & $69.4 \%$ & - & - & $30.6 \%$ & - & - & 18,708 \\
\hline 5 - Castilla & $90.0 \%$ & - & - & $10.0 \%$ & - & - & 12,597 \\
\hline 6 - Doce de Octubre & $84.8 \%$ & $15.2 \%$ & - & - & - & - & 19,909 \\
\hline 7 - Robledo & $80.1 \%$ & $10.1 \%$ & - & $9.7 \%$ & - & - & 20,674 \\
\hline 8 - Villa Hermosa & $95.0 \%$ & - & - & $5.0 \%$ & - & - & 21,819 \\
\hline 9 - Buenos Aires & $89.9 \%$ & - & - & $10.1 \%$ & - & - & 17,549 \\
\hline 10 - La Candelaria & $49.9 \%$ & - & $14.7 \%$ & $35.3 \%$ & - & - & 11,274 \\
\hline 11 - Laureles Estadio & $29.8 \%$ & - & $5.1 \%$ & $65.1 \%$ & - & - & 9,832 \\
\hline 12 - La América & $90.0 \%$ & - & - & $10.0 \%$ & - & - & 8,868 \\
\hline 13 - San Javier & $80.2 \%$ & $10.2 \%$ & - & $9.6 \%$ & - & - & 18,599 \\
\hline 14 - Poblado & $20.2 \%$ & - & $10.1 \%$ & $25.0 \%$ & $44.7 \%$ & - & 8,747 \\
\hline 15 - Guayabal & $36.2 \%$ & - & $39.4 \%$ & $24.4 \%$ & - & - & 668 \\
\hline 16 - Belén & $85.0 \%$ & - & - & $15.0 \%$ & - & - & 21,950 \\
\hline
\end{tabular}

Figure 5 shows the homeless estimation, while Figure 6 shows the unemployed estimation, both at county level.

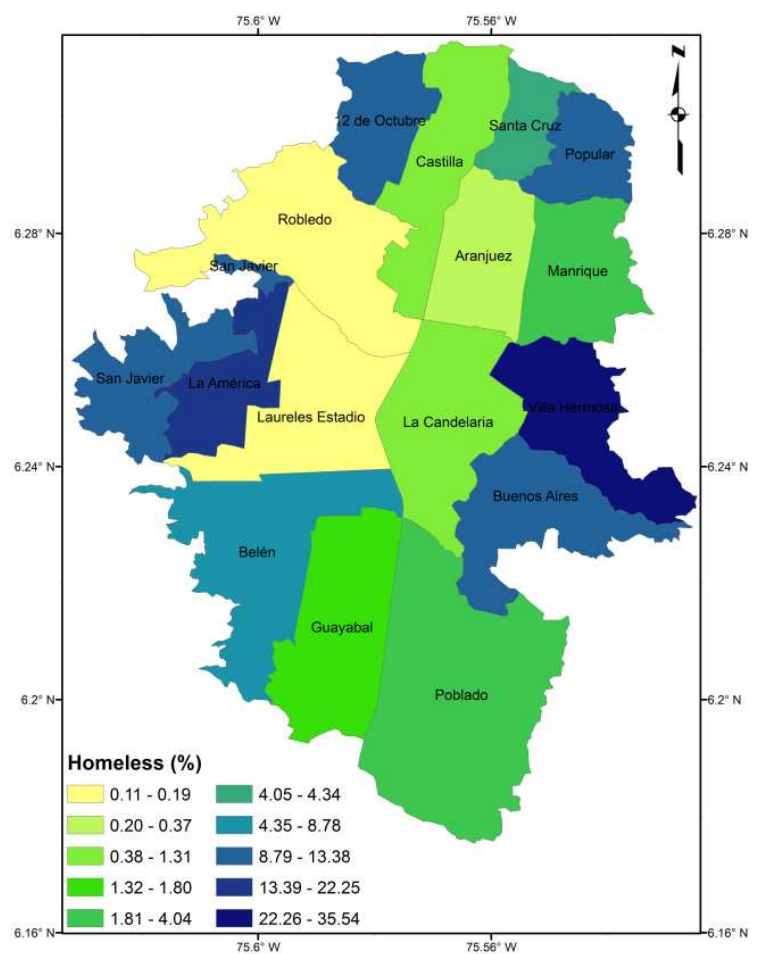

Figure 5 Homeless estimation for Medellín

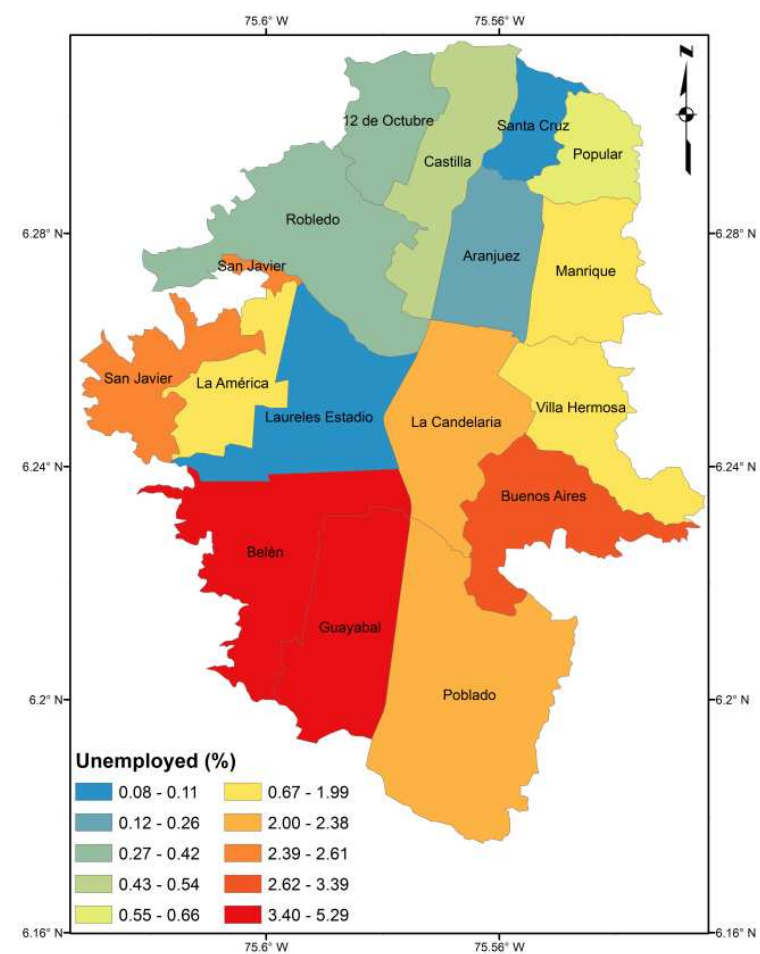

Figure 6 Unemployed estimation for Medellín

Figures 7 and 8 show the expected deaths and injuries estimation due to the occurrence of this event where results have been grouped again at county level and per hundred thousand inhabitants. 


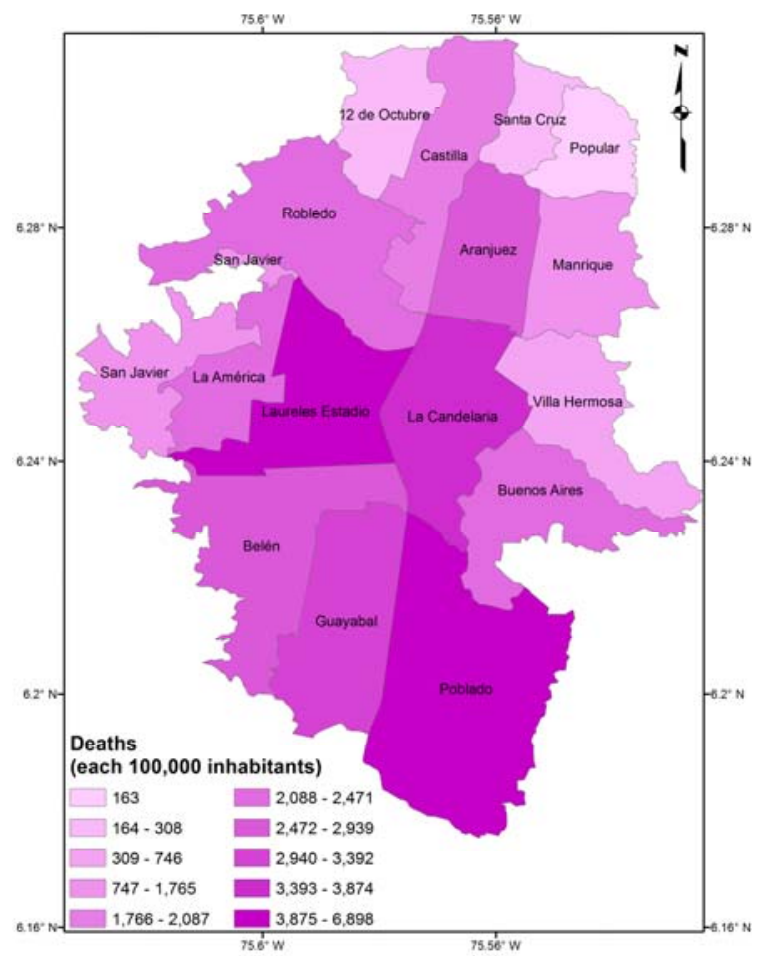

Figure 7 Deaths estimation for Medellín

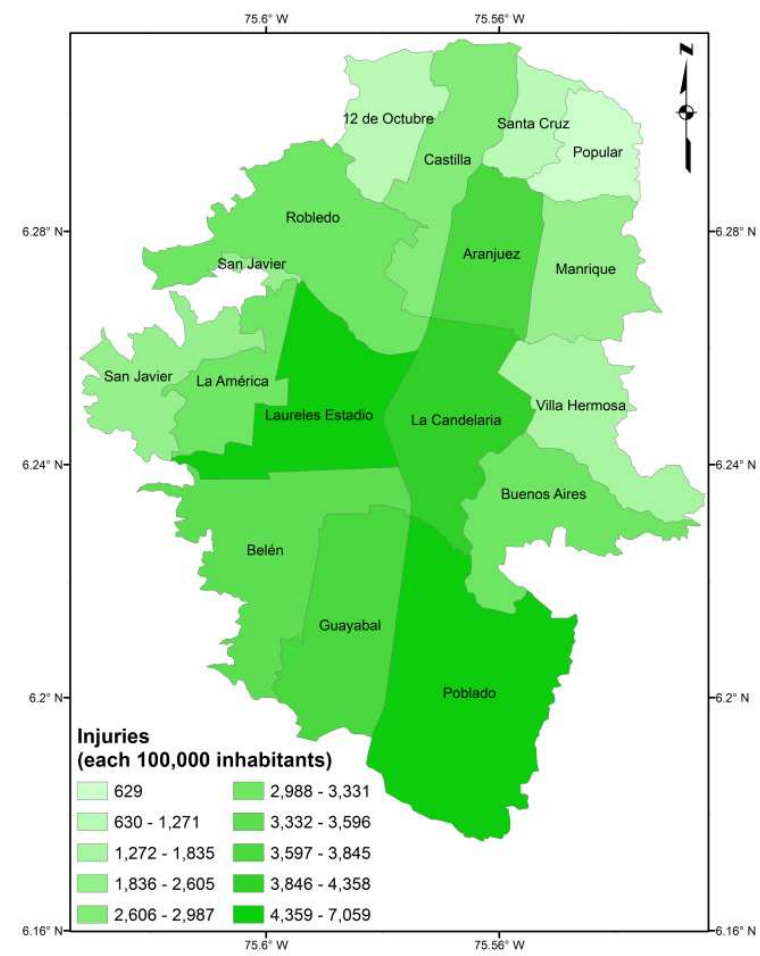

Figure 8 Injuries estimation for Medellín

It can be observed from these results that homelessness and unemployment estimations are higher for Villa Hermosa, La América, Belén, Guayabal and Manrique counties, while higher death rates due to the occurrence of an event with those characteristics are expected in Poblado and Laureles-Estadio counties. Even though these two counties have the highest income levels, they have high human density indexes and high-rise buildings with similar characteristics that are more vulnerable, from the deaths and injuries point of view, if compared with low-rise masonry units.

\section{HOLISTIC SEISMIC RISK ASSESSMENT OF MEDELLÍN}

A comprehensive risk management strategy has to be based on a multidisciplinary approach that takes into account not only the physical damage and the direct impact but also a set of socioeconomic factors that favour the second order effects and consider the intangible impact in case an earthquake event strikes the city (Cardona and Hurtado 2000; Benson 2003; Cannon 2003; Cutter et al. 2003; Davis 2003; Carreño et al. 2007; Barbat et al. 2010; Khazai et al. 2014). This can be achieved by using a holistic seismic risk assessment where physical damages are aggravated by a set of socioeconomic conditions allowing comprehensive risk evaluations that are useful for decision-making processes. This approach also allows quantifying the resilience of the analysed communities, that is, their capacity to cope with the negative effects after the occurrence of an earthquake. Detailed information about this methodology can be found in Carreño (2006), Carreño et al. (2007) and Barbat et al. (2011).

The methodology used in this study does not require the use of the exact same factors in each case study, not even in terms of the number of descriptors used, as long as the characteristics to be captured are well reflected by the ones that are chosen. The explanation is that, depending on prevalent conditions of the area under analysis, some factors can be more relevant than others. For this study, physical damage is obtained from the results of the 
probabilistic approach, already shown in section 2, which is considered to have a higher robustness if compared with previous holistic seismic risk evaluations performed before because of the available information and its quality (Carreño et al. 2007; Marulanda et al. 2013).

As it was mentioned before, holistic seismic risk analysis can be performed at different scales but also can account for multi-hazard approaches (Jaramillo 2014). For this study, the resolution level has been set to counties and the hazard limited to earthquakes since this is the only catastrophic peril expected for the city.

\subsection{Methodology for the holistic risk assessment}

Applying the holistic risk evaluation methodology proposed by Cardona (2001) and Carreño et al. (2007), the urban seismic risk index USR $i$ is calculated starting from a physical risk index, $R_{F}$, and an aggravating coefficient, $F$, which accounts for the socioeconomic fragility and lack of resilience of the analysis area. USR $i$ is calculated by using the equation

$$
U S R i=R_{F}(1+F)
$$

known in the literature as Moncho's Equation. The physical risk index, $R_{F}$, is calculated considering a set of factors as well as their associated weights by means of the following expression:

$$
R_{F}=\sum_{i=1}^{p} F_{R F i} \cdot w_{R F i}
$$

where $F_{R F i}$ are the $p$ physical risk factors and $w_{R F i}$ their corresponding weights. In this case, 8 factors were considered to obtain $R_{F}$ which were calculated from the results of the probabilistic seismic risk analysis of the buildings in Medellín described in section 2, in which both their structural characteristics and their mean occupation values were considered.

The aggravating coefficient, $F$, is calculated as follows:

$$
F=\sum_{i=1}^{m} F_{F S i} \cdot w_{F S i}+\sum_{j=1}^{n} F_{F R j} \cdot w_{F R j}
$$

where $F_{F S i}$ and $F_{F R j}$ are the aggravating factors, $w_{F S i}$ and $w_{F R j}$ are the associated weights of each $i$ and $j$ factor and $m$ and $n$ are the total number of factors for social fragility and lack of resilience, respectively. For this case, 9 descriptors were used to capture the social fragility conditions on each county while 6 descriptors are considered to capture the lack of resilience. Most of the descriptors were obtained using data from the local authorities (Alcaldía de Medellín 2012a; 2012b; Proantioquia et al. 2012; DAP 2012) with the exception of the calculation of public areas and distances to the closest hospitals and health centres, where geographical information system (GIS) tools were used. Figure 9 shows the summary of the descriptors used in this analysis where the ones denoted as $F_{R F i}$ are related to the physical risk index, the ones denoted as $F_{F S i}$ are related to the social fragility and the ones denoted as $F_{F R I}$ are related to the lack of resilience. 
The selection of the descriptors for $R_{F}$ was based on the outcomes that could be extracted from the fully probabilistic seismic risk analysis, while existing and available indicators that capture social fragility and lack of resilience issues were selected for the evaluation of $F$.

\begin{tabular}{|l|l|l|}
\hline$F_{R F 1}$ & AAL commercial sector & $\boldsymbol{w}_{\boldsymbol{R} \boldsymbol{F}}$ \\
\hline$F_{R F 2}$ & AAL industrial sector & $\boldsymbol{w}_{\boldsymbol{R} \boldsymbol{F} 2}$ \\
\hline$F_{R F 3}$ & AAL institutional sector & $\boldsymbol{w}_{\boldsymbol{R} \boldsymbol{F}}$ \\
\hline$F_{R F 4}$ & AAL residential sector & $\boldsymbol{w}_{\boldsymbol{R} \boldsymbol{F}}$ \\
\hline$F_{R F 5}$ & Expected injured & $\boldsymbol{w}_{\boldsymbol{R} \boldsymbol{F}}$ \\
\hline$F_{R F 6}$ & Expected deaths & $\boldsymbol{w}_{\boldsymbol{R} \boldsymbol{F}}$ \\
\hline$F_{R F 7}$ & Expected unemployed & $\boldsymbol{w}_{\boldsymbol{R} \boldsymbol{F} 7}$ \\
\hline$F_{R F 8}$ & Expected homeless & $\boldsymbol{w}_{\boldsymbol{R} \boldsymbol{F} 8}$ \\
\hline
\end{tabular}

\begin{tabular}{|l|l|l|}
\hline$F_{F S 1}$ & Violent deaths rate & $\boldsymbol{w}_{F S 1}$ \\
\hline$F_{F S 2}$ & Quality life index & $\boldsymbol{w}_{F S 2}$ \\
\hline$F_{F S 3}$ & Mortality rate & $\boldsymbol{w}_{F S 3}$ \\
\hline$F_{F S 4}$ & Illiteracy rate & $\boldsymbol{w}_{F S 4}$ \\
\hline$F_{F S 5}$ & Poor connection to electricity net. & $\boldsymbol{w}_{F S 5}$ \\
\hline$F_{F S 6}$ & Poor connection to water network & $\boldsymbol{w}_{F S 6}$ \\
\hline$F_{F S 7}$ & Poor connection to sewage net. & $\boldsymbol{w}_{F S 7}$ \\
\hline$F_{F S 8}$ & No access to public health care & $\boldsymbol{w}_{F S 8}$ \\
\hline$F_{F S 9}$ & Population density & $\boldsymbol{w}_{F S 9}$ \\
\hline$F_{F R 1}$ & Public area & $\boldsymbol{w}_{F R 1}$ \\
\hline$F_{F R 2}$ & Distance to closest hospital & $\boldsymbol{w}_{F R 2}$ \\
\hline$F_{F R 3}$ & Distance to closest health centre & $\boldsymbol{w}_{F R 3}$ \\
\hline$F_{F R 4}$ & Human development index & $\boldsymbol{w}_{F R 4}$ \\
\hline$F_{F R 5}$ & Development level & $\boldsymbol{w}_{F R 5}$ \\
\hline$F_{F R 6}$ & Emergency operation level & $\boldsymbol{w}_{F R \boldsymbol{6}}$ \\
\hline
\end{tabular}

Urban Seismic

Risk Index USRi

Figure 9 Factors used for the holistic seismic risk evaluation in Medellín

It is evident that each of the factors used in the calculation of the USRi captures different aspects and is quantified in different units. Because of that, certain scaling procedures are needed to standardize the values of each descriptor and convert them into commensurable factors. In this case, transformation functions were used to standardize the physical risk, social fragility and lack of resilience factors selected for this study. Some of them are shown in Figure 10. The factors and their units, as well as the [min, max] values are shown on the abscissa and also, depending on the nature of the descriptor, the shape and characteristics of the functions vary and, because of that, for example functions related to descriptors of the physical risk have an increasing shape while those related to resilience have a decreasing one; that is, the higher the value of the factors, the lower their aggravation. The transformation functions can be understood as risk and aggravating probability distribution functions or as the membership functions of the linguistic benchmarking of high risk or high aggravation. 

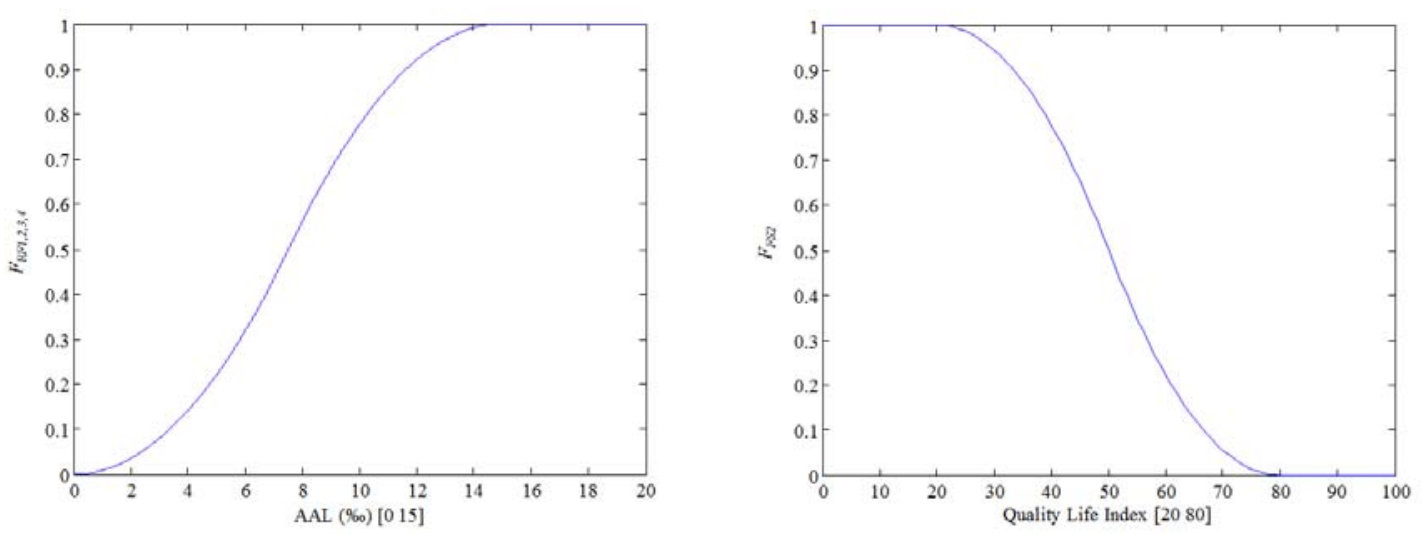

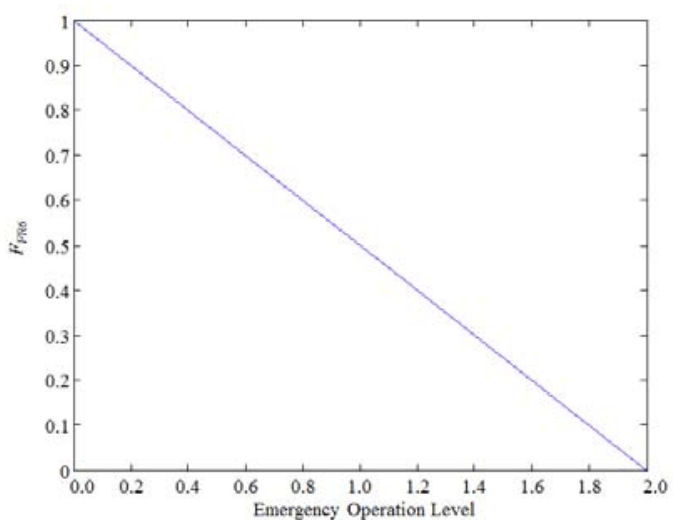

Figure 10 Examples of transformation functions

The values on the abscissa of the transformation functions correspond to the values of the descriptors while the ordinate corresponds to the final value of each factor, either related to the physical risk or to the aggravating factor. In all cases, values of the factor lie between 0 and 1. Since the transformation functions are membership functions, for high risk and aggravating coefficient levels, 0 corresponds to non-membership while 1 means full membership. Limit values, denoted as $X_{M I N}$ and $X_{M A X}$ are defined by using expert criteria and information about previous disasters in the region. Relative weights $w_{F S i}$ and $w_{F R j}$ that associate the importance of each of the factors on the index calculation are obtained by using an Analytic Hierarchy Process (AHP) that gives ratio scales from both discrete and continuous paired comparisons (Saaty and Vargas 1991; Carreño 2006; Carreño et al. 2007). AHP process was based on participation of local stakeholders and national disaster risk reduction and management experts for the definition of the weights of the aggravating coefficient factors, while, for the ones associated to the physical risk factors, besides the above mentioned participants, the authors also participated.

Tables 5 and 6 present the associated weights for the physical risk and the aggravating coefficient factors. 


\subsection{Results of the holistic risk assessment for Medellín}

Table 6 Weights for the aggravating coefficient factors

\begin{tabular}{|c|c|}
\hline Factor & Weight \\
\hline$F_{F S 1}$ & 0.03 \\
\hline$F_{F S 2}$ & 0.06 \\
\hline$F_{F S 3}$ & 0.03 \\
\hline$F_{F S 4}$ & 0.12 \\
\hline$F_{F S 5}$ & 0.05 \\
\hline$F_{F S 6}$ & 0.05 \\
\hline$F_{F S 7}$ & 0.05 \\
\hline$F_{F S 8}$ & 0.10 \\
\hline$F_{F S 9}$ & 0.07 \\
\hline$F_{F R 1}$ & 0.08 \\
\hline$F_{F R 2}$ & 0.04 \\
\hline$F_{F R 3}$ & 0.08 \\
\hline$F_{F R 4}$ & 0.08 \\
\hline$F_{F R 5}$ & 0.06 \\
\hline$F_{F R 6}$ & 0.10 \\
\hline
\end{tabular}

This section presents the results obtained using the methodology in terms of $R_{F}, F$ and USRi. Table 7 presents the results of this study for the 16 counties of Medellín sorted in descending order according to the USRi results. 
Table 7 Results obtained for Medellín

\begin{tabular}{|l|c|c|c|}
\hline \multicolumn{1}{|c|}{ County } & $\boldsymbol{R}_{\boldsymbol{F}}$ & $\boldsymbol{F}$ & $\boldsymbol{U S R \boldsymbol { i }}$ \\
\hline Villa Hermosa & 0.31 & 0.28 & 0.39 \\
\hline La América & 0.28 & 0.32 & 0.37 \\
\hline Poblado & 0.28 & 0.20 & 0.34 \\
\hline Laureles Estadio & 0.24 & 0.27 & 0.31 \\
\hline La Candelaria & 0.22 & 0.33 & 0.29 \\
\hline Buenos Aires & 0.22 & 0.28 & 0.28 \\
\hline Guayabal & 0.18 & 0.29 & 0.23 \\
\hline Belén & 0.17 & 0.20 & 0.21 \\
\hline Aranjuez & 0.12 & 0.32 & 0.16 \\
\hline San Javier & 0.10 & 0.41 & 0.15 \\
\hline Castilla & 0.10 & 0.30 & 0.13 \\
\hline Robledo & 0.09 & 0.31 & 0.12 \\
\hline Manrique & 0.08 & 0.33 & 0.10 \\
\hline Doce de Octubre & 0.07 & 0.28 & 0.08 \\
\hline Popular & 0.06 & 0.34 & 0.08 \\
\hline Santa Cruz & 0.02 & 0.29 & 0.02 \\
\hline
\end{tabular}

Since the results have been obtained using a GIS tool, maps with the distribution of the results can be built and could be of help to decision-makers for communicative and comparison purposes among them. For each index, a ranking has been generated to classify each result into low, medium-low, medium-high, high and very high categories. Figure 11 shows the $R_{F}$ at county level. The highest $R_{F}$ values are found in Villa Hermosa and Poblado while the lowest values are found in Popular and Santa Cruz. This is an interesting finding since the two lowest results correspond to low-income areas and can be explained by the low injury and death rates associated to the building classes in these areas since they correspond to nonengineered systems, typically made from light materials, that do not represent, in general terms, harm to the inhabitants. Another finding of interest is that, even though Poblado has the best socioeconomic conditions, a disorganized urbanization process has been developed in the area and high rise structures, not always complying with the requirements established by the Colombian earthquake resistant building code, have been built. Its large $R_{F}$ value is explained by the high physical vulnerability and the consequences in terms of expected deaths, injured and homeless in it. In terms of the categories used to aggregate the results, only Villa Hermosa has a high physical risk index category, while medium-high values are found at Poblado, Laureles Estadio, La Candelaria, La América and Buenos Aires.

In all counties, the descriptors that, after considering their relative weights, contribute the most to $R_{F}$ are the ones that account for deaths and homeless. The estimation of these descriptors is directly related to the physical damage of the dwellings and, thus, a reduction on these descriptors can be achieved through the development of retrofitting schemes of at least essential buildings such as hospitals and schools, while also decreasing the physical vulnerability of new infrastructure by enforcement on the use of the earthquake building code. Reducing the existing vulnerability is an ideal approach, but incentives to do so must be created, even more when seismic risk perception is low because of the low occurrence rate of earthquakes in Medellín. 


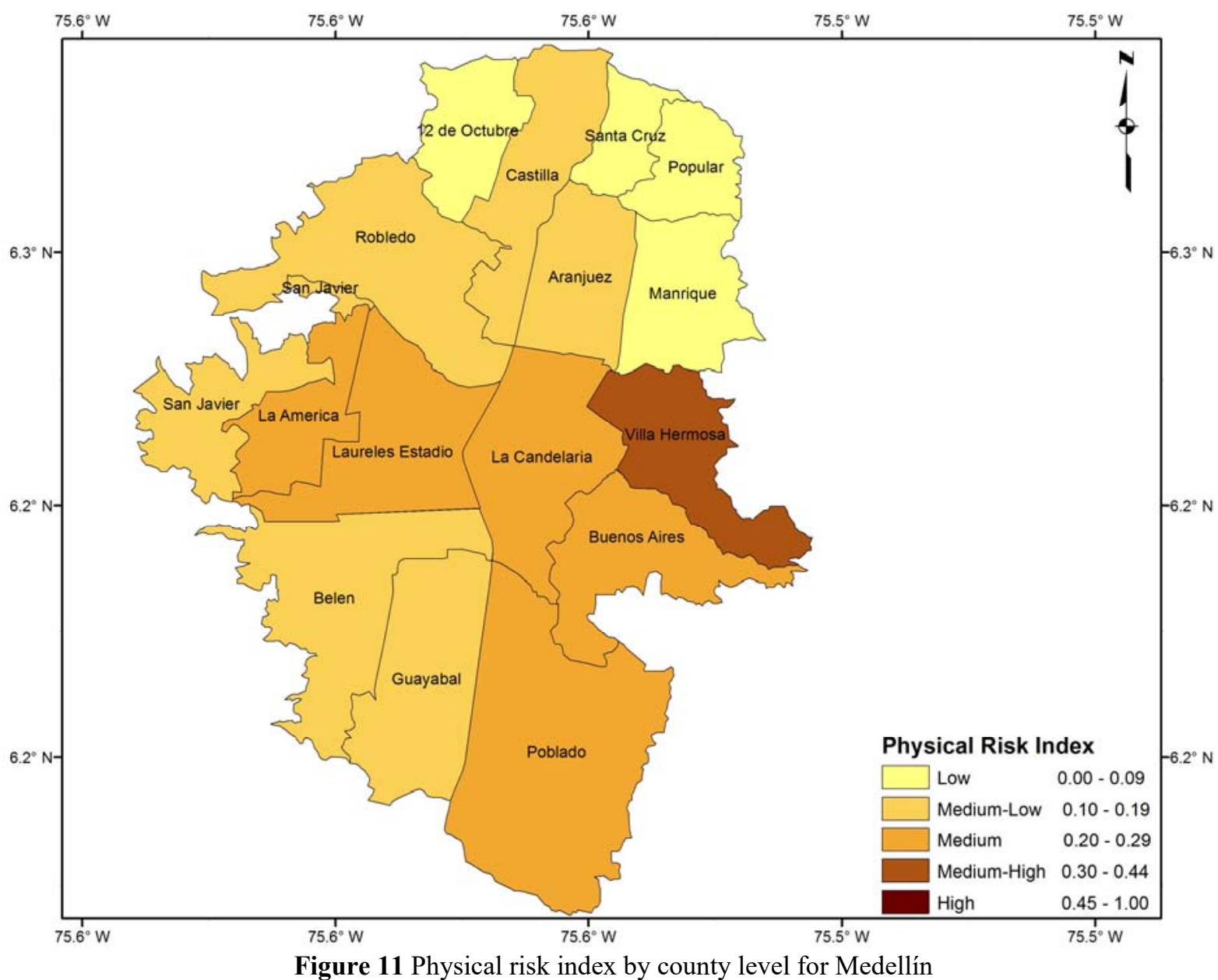

Figure 12 shows the aggravating coefficient, $F$, at county level. The highest $F$ is found at $S a n$ Javier which constitutes a problematic area of the city from the social, urban planning and security perspective. Additionally, marginal areas, such as the ones that exist in Villa Hermosa and Popular, contribute to the large aggravating coefficients. Better characteristics can be found in Laureles-Estadio, and Poblado which are the wealthiest and more urban developed areas, though not necessarily organized, of Medellín. Belén constitutes an interesting case because, despite the fact that it does not have the best economic conditions, it presents a low aggravating coefficient because of the presence of several hospitals and medical centres.

From the results, the descriptors for social fragility and lack of resilience that most contribute to the aggravating coefficient, $F$, are the population density and the public area, respectively. These issues can be addressed by integrating the results with urban planning actions that can account for the improvement of today's conditions regarding those topics and need to be included in the development plans of the city. The population density captured here is not proportional to the casualties estimation performed for the estimation of $R_{F}$ since the vulnerability functions vary from building class to building class and, as shown in Table 4, that distribution has significant variations along different areas of the city. 
Figure 13 shows the USRi at county level. The highest USRi is found in Villa Hermosa followed by Poblado since a high $R_{F}$ value is combined with an intermediate $F$, whereas important increases in the final results are observed in La América, Laureles Estadio, Buenos Aires and La Candelaria, reflecting the importance of accounting for socioeconomic characteristics, additional to the traditional physical seismic risk results. From here, it can be concluded that even if income levels are useful to determine the vulnerability of a certain area, from either the physical or social dimension, it is not the only driver that influences the final result. Finally, Figure 14 shows the ranking in terms of the USRi to better understand the differences on the results between the counties. 

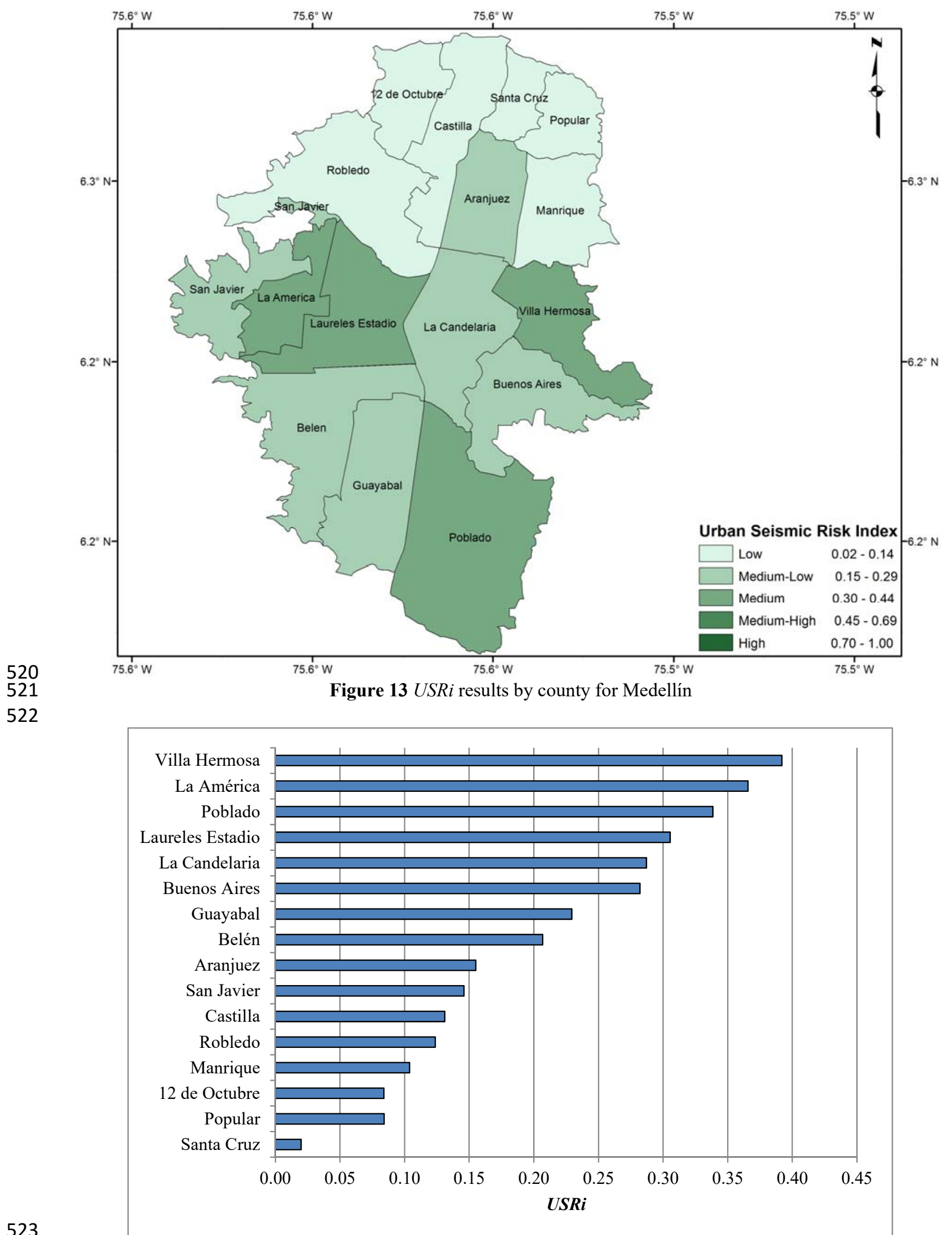

Figure 14 USRi ranking for Medellín 


\subsection{Disaggregation of the holistic assessment of risk at county level}

Given that the USR $i$ is a composite indicator, after obtaining the final result it is possible to disaggregate it and to see the contribution of the different descriptors related to the physical risk and/or the social fragility and lack of resilience. This disaggregation can be made for the 16 counties of Medellín. As an example, the mentioned disaggregation is presented for the Villa Hermosa County, the one with the highest USRi.

For $R_{F}$, as it can be seen in Figure 15, the descriptor with higher participation is the $F_{R F 7}$ (using the same notation as Figure 9) which is related to the number of homeless which, as was explained above, is directly related to the calculated MDR given the occurrence of the selected earthquake event. For the social fragility descriptors, the one with higher participation is $F_{F S 1}$ related to the violent deaths rate, as it can be seen in Figure 16. Finally, for the lack of resilience descriptors, the one with higher overall participation is $F_{F R l}$, associated with the available public space, as shown in Figure 17.

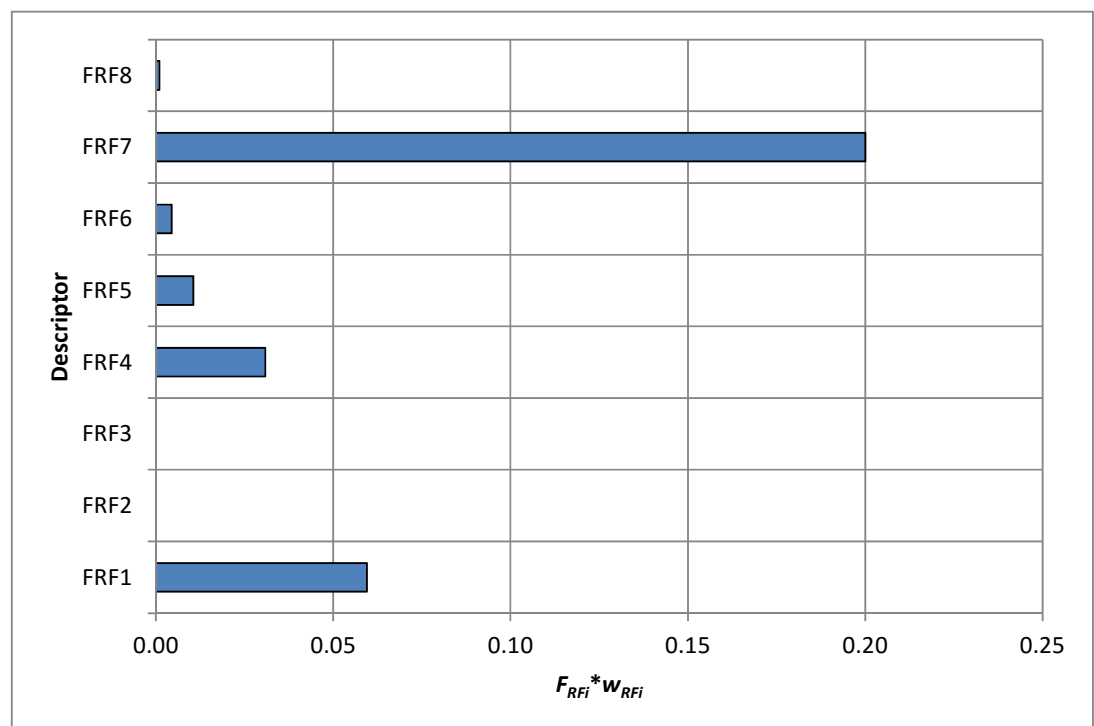

Figure $15 F_{R F i}$ disaggregation for Villa Hermosa County

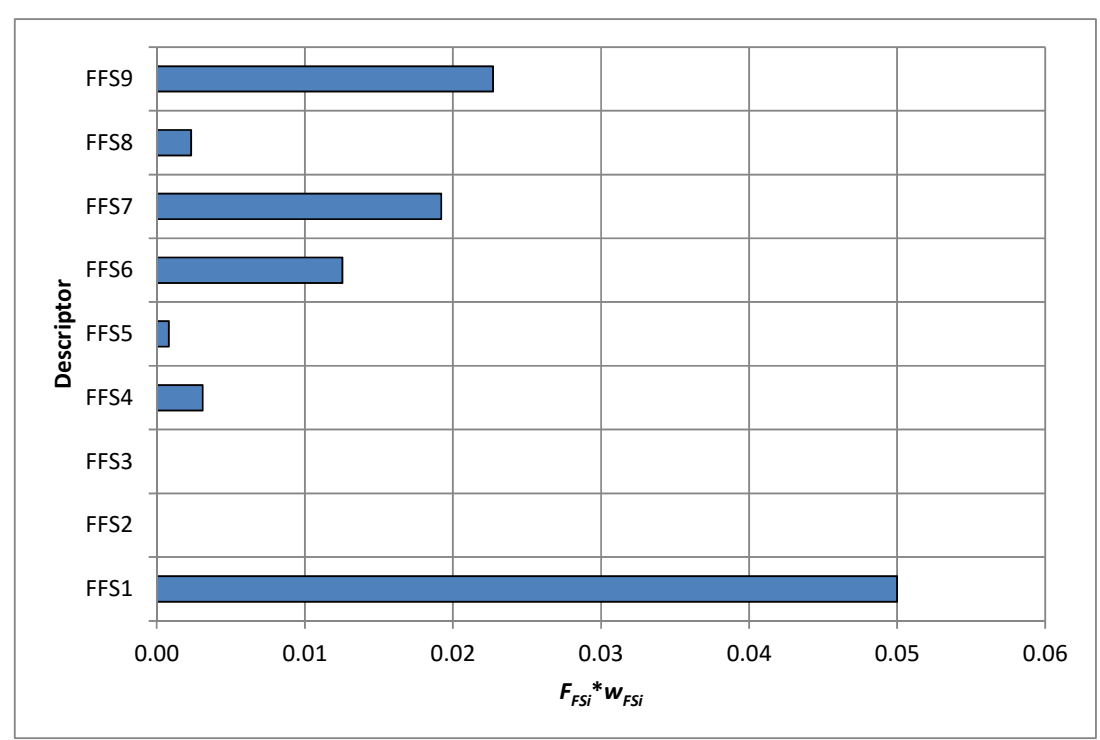

Figure $16 F_{F S i}$ disaggregation for Villa Hermosa County 


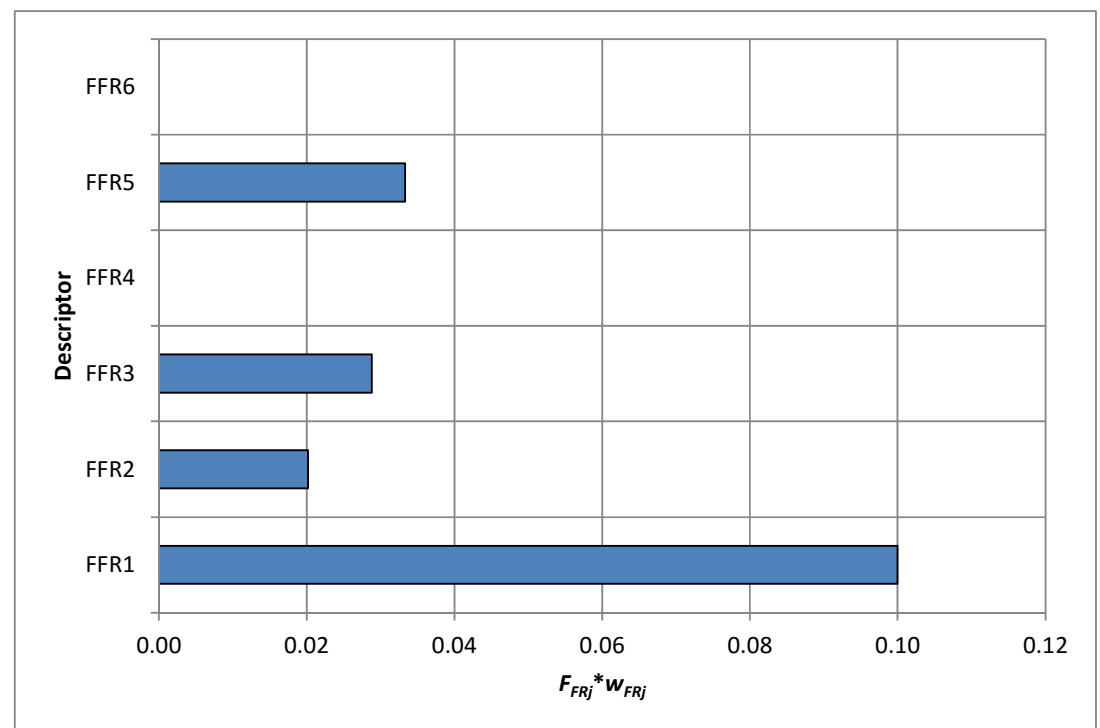

Figure $17 F_{F R i}$ disaggregation for Villa Hermosa County

Besides allowing identifying the factors that mostly contribute to the USR $i$ either in overall terms or by category, the disaggregation process highlights the necessity of a multidisciplinary approach in a comprehensive seismic risk assessment framework since the risk drivers may be related to different origins such as building code compliance and enforcement, urban planning and territorial management, as it has been explained for the Villa Hermosa County. The results of this study can be integrated into other assessments related to the performance of the disaster risk management strategies in the city, such as the one developed by López (2010). Also, incorporating these aspects in the disaster risk management scheme at local level is of high importance in a city where the perception of seismic hazard and risk is low by its inhabitants, but, where not only because of the geological and tectonic conditions but to the social, economic and urban planning ones, the occurrence of an earthquake can lead to disastrous consequences.

\section{CONCLUSIONS}

Probabilistic risk assessment methodologies, such as the one used by the CAPRA Platform, include advanced tools to quantify expected losses on a portfolio of exposed assets given the occurrence of hazardous events. These tools must be understood as models that are intended to represent a reliable order of magnitude of the expected losses and not to predict events and exact amounts. It is important to obtain physical risk results using a probabilistic approach, considering the inherent uncertainties, but it is also essential to move towards the use of the results within a multidisciplinary disaster risk management framework, such as the one of this study. When calculating physical losses with this approach, it is important to take into account the correlation between the losses since its exclusion may lead to underestimation of them; details about how this issue is dealt with, within the CAPRA Platform, can be found in Salgado-Gálvez et al. (2014a).

Regarding the risk identification process, building by building information is useful since the individual location of a dwelling in a large city such as Medellín can lead to significant changes on its individual expected damages and losses due to geographical variations on the hazard intensities, a fact that is heightened when a seismic microzonation study is included. On the other hand, when communicating aggregated risk through maps, results should be grouped in larger divisions such as counties in order to avoid misleading conclusions. 
Catastrophe risk models are based on the large numbers law, where a statistically significant number of elements are required to obtain a reliable estimation of the risk results but seen as a whole and not on an individual basis. For that reason the physical risk results have been grouped at county level which constitutes the administrative division for Medellín. Grouping results on administrative areas can also facilitate the decision-making process since comprehensive schemes can be developed by establishing actions that, in overall, can reduce today's risk conditions.

It is relevant to quantify seismic risk from both a physical and a holistic perspective because even though earthquakes are not the most common hazardous event in the city if compared to flash floods or landslides (which are not considered catastrophic); an event like this can lead to correlated damages and deaths, as well as to important disruptions occurring at the same time in different zones within the city. Also, though the uncertainties related to the physical seismic risk assessment have been accounted for, future research is needed in order to incorporate the ones existing in the considered socio-economic characteristics (Burton and Silva 2014). Those cannot be handled by means of probability distributions but nevertheless it is important to highlight that within the methodology explained and used herein, sensitivity tests on input data, weight and transformation functions using Monte Carlo simulations have shown how, at urban level, the risk rankings and risk level ranges derived from the composite indicator are robust (Marulanda et al 2009).

Seismic risk assessed from a hard, soft or holistic approach is intended to contribute to the effectiveness of management strategies which largely depend on the decision-making process. Though this methodology can be understood as a simplified representation of the seismic risk at urban level, it performs a multidisciplinary approach that accounts not only for the physical damage but for social, institutional, economic and organizational issues that influence the risk results. Vulnerability is not only seen as a risk factor determined by the physical characteristics of a group of buildings, but also as being related to social fragility and lack of resilience of the exposed communities, while poverty must be understood as a vulnerability driver and not vulnerability itself.

A disaster risk reduction management scheme must involve an interdisciplinary process and the holistic evaluation contributes to this process, not only by considering the socioeconomic factor but by being a useful way to communicate risk through the identification of the critical areas of a city where the vulnerability is assessed considering different perspectives.

Finally, these kind of evaluations can be periodically updated to evaluate the effectiveness of the prevention and mitigation strategies defined for the area of analysis whilst highlighting the most important measures to be taken that are needed to decrease either the physical vulnerability, the social fragility conditions and/or the lack of resilience.

\section{ACKNOWLEDGMENTS}

The authors are grateful for the support of the Ministry of Education and Science of Spain "Enfoque integral y probabilista para la evaluación del riesgo sísmico en España"CoPASRE (CGL2011-29063). Also to the Spain's Ministry of Economy and Competitiveness in the framework of the researcher's formation program (FPI) and the support of the "Paul C. Bell, Jr." risk management program of the Florida International University (FIU). This work has also been partially sponsored by the European Commission (project DESURBS-FP7- 
2011-261652). Finally the authors would like to thank an anonymous reviewer whose comments helped to improve the original version of the manuscript.

\section{REFERENCES}

Ahmad N., Ali Q., Crowley H. and Pinho R. (2014). Earthquake loss estimation of residential buildings in Pakistan. Nat. Hazards. DOI: 10.1007/s11069-014-1174-8.

Alcaldía de Medellín, (2012a). Encuesta de calidad de vida 2011. Departamento Administrativo de Planeación.

Alcaldía de Medellín, (2012b). Indicadores básicos. Situación de salud en Medellín 2011. Secretaría de Salud de Medellín.

Alcaldía de Medellín. (2010). Geonetwork. http://poseidon.medellin.gov.co/geonetwork/srv/es/main.home Accessed January $12^{\text {th }} 2013$.

Asociación Colombiana de Ingeniería Sísmica-AIS. (2010). Estudio General de Amenaza Sísmica de Colombia. Comité AIS-300. Bogotá D.C., Colombia.

Asociación Colombiana de Ingeniería Sísmica-AIS. (1996). Estudio General de Amenaza Sísmica de Colombia. Comité AIS-300. Bogotá D.C., Colombia.

Barbat A.H., Carreño M.L., Cardona O.D. and Marulanda M.C. (2011). Evaluación holística del riesgo sísmico en zonas urbanas Revista int. de métodos numér. para calc. y diseño en ing. 27(1):3-27.

Barbat A.H., Carreño M.L., Pujades L.G., Lantada N., Cardona O.D. and Marulanda M.C. (2010). Seismic vulnerability and risk evaluation methods for urban áreas. A review with application to a pilot area. Struct. and infraestruct. eng. 6(1-2):17-38.

Bazzurro P. and Luco N. (2005). Accounting for uncertainty and correlation in earthquake loss estimation. ICOSSAR. ISBN 9059860404.

Benson C. (2003). The economy-wide impact of natural disasters in developing countries. Thesis. University of London.

Birkmann J., Cardona O.D., Carreño M.L., Barbat A.H., Pelling M., Schneiderbauer S., Kienberger S., Keiler M., Alexander D., Zeil P. and Welle T. (2013). Framing vulnerability, risk and societal responses: the MOVE framework. Nat. Hazards 67:193-211. DOI: 10.1007/s11069-013-0558-5.

Bommer J.J. and Crowley H. (2006). The influence of ground-motion variability in earthquake loss modelling. Bull. of earthq. Eng. DOI: 10.1007/s10518-006-9008-z.

Brink S.A. and Davidson R.A. (2014). Framework for Comprehensive Assessment of a City's Natural Disaster Risk. Earthq. spectra. DOI: 10.1193/021914EQS031M. In press.

Burton C.G., Khazai B. and Silva V. (2014). Social vulnerability and integrated risk assessment within the Global Earthquake Model. Proceedings of the Tenth U.S. National conference on Earthquake Engineering. Anchorage, United States of America.

Burton C.G. and Silva V. (2014). Integrated risk modelling within the Global Earthquake Model (GEM): Test case application for Portugal. Proceedings of the Second European Conference on Earthquake Engineering and Seismology. Istambul, Turkey.

Caers J. (2011). Modeling Uncertainty in the Earth Sciences. Wiley-Blackwell. 
Cannon T. (2003). Vulnerability analysis, livelihoods and disasters components and variables of vulnerability: modelling and analysis for disaster risk management. Universidad Nacional de Colombia. Manizales.

Cardona O.D. (2009). La gestión financiera del riesgo de desastres: Instrumentos financieros de retención y transferencia para la Comunidad Andina. PREDECAN. Lima, Perú.

Cardona O.D. (2001). Estimación holística del riesgo sísmico utilizando sistemas dinámicos complejos. Ph.D. Thesis. Universidad Politécnica de Cataluña. Barcelona, Spain.

Cardona O.D. and Hurtado J. (2000). Holistic seismic risk estimation of a metropolitan center. $12^{\text {th }}$ World Conference on Earthquake Engineering, Auckland, New Zealand.

Cardona O.D., Ordaz M., Mora M., Salgado-Gálvez M.A., Bernal G.A., Zuloaga-Romero D., Marulanda M.C., Yamín L. and González D. (2014). Global risk assessment: A fully probabilistic seismic and tropical cyclone wind risk assessment. Int. j. of disaster risk reduct. 10:461-476. DOI:10.1016/j.ijdrr.2014.05.006.

Cardona O.D., Ordaz M., Reinoso E., Yamín L.E. and Barbat A.H. (2012). CAPRA - Comprehensive Approach to Probabilistic Risk Assessment: International Initiative for Risk Management Effectiveness. $15^{\text {th }}$ World Conference on Earthquake Engineering. Lisbon, Portugal.

Cardona O.D., Ordaz M., Reinoso E., Yamín L.E. and Barbat A.H. (2010). Comprehensive Approach to Probabilistic Risk Assessment (CAPRA); International initiative for disaster risk management effectiveness. $14^{\text {th }}$ European conference on earthquake engineering, Ohrid, Macedonia.

Cardona O.D., Ordaz M.G., Yamín L.E., Marulanda M.C. and Barbat A.H. (2008a). Earthquake loss assessment for integrated disaster risk management. J. of earthq. eng. 12(S2):48-59.

Cardona O.D., Ordaz M.G., Marulanda M.C. and Barbat A.H. (2008b). Estimation of probabilistic seismic losses and the public economic resilience - An approach for macroeconomic impact evaluation. J. of earthq. eng. 12(S2):60-70.

Carreño M.L. (2006). Técnicas innovadoras para la evaluación del riesgo sísmico y su gestión en centros urbanos: Acciones ex ante y ex post. Doctoral Thesis. Universidad Politécnica de Cataluña, Barcelona, Spain.

Carreño M.L., Cardona O.D. and Barbat A.H. (2007). Urban seismic risk evaluation: a holistic approach. Nat. Hazards. 40(1):137-172.

Carreño M.L., Cardona O.D. and Barbat A.H. (2012). New methodology for urban seismic risk assessment from a holistic perspective. Bull. of earthq. eng. 10(2):547-565.

Carreño M.L., Cardona O.D. and Barbat A.H. (2014). Método numérico para la evaluación holística del riesgo sísmico utilizando la teoría de conjuntos difusos. Revista int. de métodos numér. para calc. y diseño en ing. 30(1):24-34.

CIMNE-RAG (2014). Holistic risk evaluation tool EvHo V1.0. Program for computing holistic risk at urban level. Centro Internacional de Métodos Numéricos en Ingeniería, CIMNE, Risk Assessment Group, RAG, Barcelona, Spain.

Crowley H., Stafford P.J. and Bommer J.J. (2008). Can earthquake loss models be validated using field observations? j.of earthq. Eng. 12:1078-1104. 
Cutter S., Boruff B. and Shirley W. (2003). Social vulnerability to environmental hazards. Social Science. 84:242-261.

Daniell J.E, Daniell K.A., Daniell T.M. and Khazai B. (2010). A country level physical and community risk index in the Asia-Pacific region for earthquakes and floods. Proceedings of the $5^{\text {th }}$ Internacional Civil Engineering Conference in the Asian Region (CECAR). Sydney, Australia.

Davis I. (2003). The effectiveness of current tools for the identification, measurement, analysis and synthesis of vulnerability and disaster risk. Universidad Nacional de Colombia. Manizales.

Departamento Administrativo de Planeación - DAP, (2012). Pobreza y condiciones de vida de los habitantes de Medellín, 2011. Observatorio de Políticas Públicas.

Evaluación de Riesgos Naturales América Latina-ERN-AL, (2011). CAPRA-GIS v2.0. Program for the probabilistic risk assessment. Available on: www.ecapra.org. Accessed May 15th 2013.

International Bank for Reconstruction and Development - IBRD, The World Bank (2013). Pacific Catastrophe Risk Assessment and Financing Initiative. Better risk information for smarter investments. Summary report.

Jaiswal K.S., Wald D.J., Earle P.S., Porter K.A. and Hearne M. (2011). Earthquake Casualty Models Within the USGS Prompt Assessment of Global Earthquakes for Response (PAGER) System. In: Human Casualties in Earthquakes. Eds: Spence R., So E. and Scawthorn C. Springer.

Jaramillo N. (2014). Evaluación holística del riesgo sísmico en zonas urbanas y estrategias para su mitigación. Aplicación a la ciudad de Mérida-Venezuela. Doctoral Thesis. Universidad Politécnica de Cataluña. Barcelona, Spain.

Khazai B., Bendimerad F., Cardona O.D., Carreño M.L., Barbat A.H. and Burton C.G. (2015). A guide to measuring urban risk resilience. Principles, tools and practice of urban indicators. Earthquake Megacities Initiative.

Khazai B., Burton C.G., Tormene P., Power C., Bernasoocchi M., Daniell J.E., Wyss B. and Henshaw P. (2014). Integrated risk modelling toolkit and database for earthquake risk assessment. Proceedings of the Second European Conference on Earthquake Engineering and Seismology. Istambul, Turkey.

Khazai B., Burton C.G., Power C. and Daniell J. (2013). Socio economic vulnerability and integrated risk project. Technical report Nr. 2. Karlsruhe Institute of Technology, Willis Research Network, The Center for Disaster Management and Risk Reduction Technology, Global Earthquake Model.

Lantada N., Irrizari J., Barbat A.H., Goula X., Roca A., Susagna T. and Pujades L.G. (2010). Seismic hazard and risk scenarios for Barcelona, Spain, using the Risk-UE vulnerability index method. Bull. of earthq. eng. 8:201-229.

Liel A.B. and Deierlein G.C. (2012). Using collapse risk assessments to inform seismic safety policy for older concrete buildings. Earthq. spectra. 28(4):1495-1521. DOI:10.1198/1.4000090.

López J. (2010). Índice de gestión de riesgo (IGR). Programa de información e indicadores de gestión del riesgo BID-IDEA. Departamento Administrativo de Planeación y Atención de Desastres. Medellín, Colombia.

Luco N. and Cornell C.A. (2007). Structure-specific scalar intensity measures for near-source and ordinary earthquake motions. Earthq. spectra. 23(2):357-392. 
Marulanda M.C., Cardona O.D., Mora M.G. and Barbat A.H. (2014). Design and implementation of a voluntary collective earthquake insurance policy to cover low-income homeowners in a developing country. Nat. Hazards. 74:2071-2088.

Marulanda M.C., Carreño M.L., Cardona O.D., Ordaz M. and Barbat A.H. (2013). Probabilistic earthquake risk assessment using CAPRA: application to the city of Barcelona, Spain. Nat. Hazards. 69:59-84. DOI: 10.1007/s11069-013-0685-z.

Marulanda M.C., Cardona O.D. and Barbat A.H. (2009). Robustness of the holistic seismic risk evaluation in urban centers using the USRi. Nat. Hazards. 49(3):501-516.

Ordaz M. (2000) Metodología para la evaluación del riesgo sísmico enfocada a la gerencia de seguros por terremoto. Universidad Nacional Autónoma de México, México D.F.

Ordaz M., Aguilar A. and Arboleda J. (2007). CRISIS 2007 V7.6, Program for computing seismic hazard. Instituto de Ingeniería. Universidad Nacional Autónoma de México.

Ordaz M., Miranda E., Reinoso E. and Pérez-Rocha L.E. (2000). Seismic loss estimation model for Mexico City. Proceedings of the 12th World Conference on Earthquake Engineering.

Paris G., Machete M, Dart R. and Haller K. (2000). Map and Database of Quaternary Faults and Folds in Colombia and Offshore Regions, USGS Open-File Report.

Park J., Bazzurro P. and Baker J.W. (2007). Modeling spatial correlation of ground motion Intensity Measures for regional seismic hazard and portfolio loss estimation. Applications of Statistics and Probability in Civil Engineering. ISBN 978-0-415-45211-3.

Proantioquia, Universidad EAFIT, Fundación Corona, Comfama, Comfenalco, Cámara de Comercio de Medellín, El Colombiano, Cámara de Comercio de Bogotá and El Tiempo (2012). Medellín cómo vamos?

Pulido N. (2003). Seismotectonics of the Northern Andes (Colombia) and the Development of Seismic Networks. Bull. of the int. inst. of seismol. and earthq. eng. Special Edition:69-76.

Renn O. (2008). Concepts of risk: An interdisciplinary review. Proceedings of the ISA Conference, Barcelona, Spain.

Saaty T. and Vargas L. (1991). Prediction, projection and forecasting: applications of the analytic hierarchy process in economics, finance, politics, games and sports. Kluwer Academic Publishers, Dordrecht.

Salgado-Gálvez M.A., Carreño M.L., Barbat A.H. and Cardona O.D. (2015a). Evaluación probabilista del riesgo sísmico en Lorca mediante simulaciones de escenarios. Revista int. de métodos numér. para calc. y diseño en ing. DOI: 10.1016/j.rimni.2014.12.001. In press.

Salgado-Gálvez M.A., Bernal G.A. and Cardona O.D. (2015b). Evaluación probabilista de la amenaza sísmica de Colombia con fines de actualización de la Norma Colombiana de Diseño de Puentes CCP-14. Revista int. de métodos numér. para calc. y diseño en ing. In press.

Salgado-Gálvez M.A., Bernal G.A., Barbat A.H., Carreño M.L. and Cardona O.D. (2015c). Probabilistic estimation of annual lost economic production due to premature deaths because of earthquakes. Hum. ecol. Risk assess. DOI: 10.1080/10807039.2015.1095072. In press. 
Salgado-Gálvez M.A., Zuloaga D., Bernal G.A., Mora M.G. and Cardona O.D. (2014a). Fully probabilistic seismic risk assessment considering local site effects for the portfolio of buildings in Medellín, Colombia. Bull. of earthq. Eng. 12:671-695. DOI: 10.1007/s10518-013-9550-4.

Salgado-Gálvez M.A., Barbat A.H., Cardona O.D., Carreño M.L., Velásquez C.A. and Zuloaga D. (2014b). Urban seismic risk index for Medellín: a probabilistic and holistic approach. Proceedings of the Second IRDR Conference. Beijing, China.

Salgado-Gálvez M.A., Zuloaga D., Bernal G.A. and Cardona O.D. (2014c). Comparación de los resultados de riesgo sísmico en dos ciudades con los mismos coeficientes de diseño sismo resistente. Rev. De Ing. 41:8-14. Universidad de Los Andes, Bogotá, Colombia.

Salgado-Gálvez M.A., Zuloaga D. and Cardona O.D. (2013). Evaluación probabilista del riesgo sísmico de Bogotá y Manizales con y sin la influencia de la Caldas Tear. Rev. De Ing. 38:6-13. Universidad de Los Andes, Bogotá, Colombia.

Salgado-Gálvez M.A., Bernal G.A., Yamín L.E. and Cardona O.D. (2010). Evaluación de la amenaza sísmica de Colombia. Actualización y uso en las nuevas normas colombianas de diseño sismo resistente NSR-10. Rev. de Ing. 32:28-37. Universidad de Los Andes, Bogotá, Colombia.

Silva V., Crowley H., Varum H. and Pinho R. (2014). Seismic risk assessment for mainland Portugal. Bull. of earthq. Eng. DOI: 10.1007/s10518-014-9630-0.

Sistema Distrital de Prevención y Atención de Emergencias - SDPAE (2002). Plan de respuesta a emergencias por terremoto en Bogotá D.C. Alcaldía de Bogotá D.C. Colombia.

Sistema Municipal Para la Atención de Desastres - SIMPAD, Universidad EAFIT, Integral, INGEOMINAS and Universidad Nacional de Colombia Sede Medellín, (1999). Instrumentación y microzonificación sísmica del área urbana de Medellín.

Taboada A., Rivera A., Fuenzalida A., Cisternas A., Philip H., Bijwaard H., Olaya J. and Rivera C. (2000). Geodynamics of the northern Andes. Subductions and intracontinental deformation (Colombia). Tecton. 19(5): 787-813.

Velásquez C.A., Cardona O.D., Mora M.G., Yamín L.E., Carreño M.L. and Barbat A.H. (2014). Hybrid loss exceedance curve (HLEC) for disaster risk assessment. Nat Hazards. 72: 455-479.

Zuloaga D., Salgado-Gálvez M.A., Cardona O.D. and Yamín L.E. (2013). Implicaciones en la estimación del riesgo sísmico de Bogotá como resultado de una nueva interpretación sismotectónica. Proceedings of the VI Congreso Nacional de Ingeniería Sísmica. Bucaramanga, Colombia. 